\title{
Thermal Processes Associated with Pelleting and Feed Phosphate Variation in Diets on Feed Manufacture and Broiler Performance
}

Ariel N. Bergeron

Follow this and additional works at: https://researchrepository.wvu.edu/etd

\section{Recommended Citation}

Bergeron, Ariel N., "Thermal Processes Associated with Pelleting and Feed Phosphate Variation in Diets on Feed Manufacture and Broiler Performance" (2017). Graduate Theses, Dissertations, and Problem Reports. 5187.

https://researchrepository.wvu.edu/etd/5187

This Thesis is protected by copyright and/or related rights. It has been brought to you by the The Research Repository @ WVU with permission from the rights-holder(s). You are free to use this Thesis in any way that is permitted by the copyright and related rights legislation that applies to your use. For other uses you must obtain permission from the rights-holder(s) directly, unless additional rights are indicated by a Creative Commons license in the record and/ or on the work itself. This Thesis has been accepted for inclusion in WVU Graduate Theses, Dissertations, and Problem Reports collection by an authorized administrator of The Research Repository @ WVU. For more information, please contact researchrepository@mail.wvu.edu. 
Thermal Processes Associated with Pelleting and Feed Phosphate Variation in Diets on Feed Manufacture and Broiler Performance

Ariel N. Bergeron

\author{
Thesis submitted \\ to the Davis College of Agriculture, Natural Resources, and Design \\ at West Virginia University \\ in partial fulfillment of the requirements for the degree of
}

Master of Science

In

Nutrition and Food Science

Joseph S. Moritz, Ph.D, Chair

Janet Tou, Ph.D

Marie Krause, Ph.D

Division of Animal and Nutritional Sciences

Morgantown, West Virginia

2017

Keywords: thermal processing, diet formulation, amino acid digestibility, performance

Copyright 2017 Ariel N. Bergeron 


\section{ABSTRACT \\ Thermal Processes Associated with Pelleting and Feed Phosphate Variation in Diets on Feed Manufacture and Broiler Performance Ariel N. Bergeron}

The objectives of the first study were to assess performance and digestible amino acid concentration of diets fed to broilers that differed in diet formulation and degree of thermal processing. Basal diets were corn, soybean meal, and DDGS based and formulations were balanced to be similar in calculated energy and digestible amino acids. Treatments were arranged in a $3 \times 3$ factorial that varied in diet formulation (Basal, Basal + Meat and Bone Meal (MBM), and Basal + Bakery Byproduct (BBP)) and degree of thermal processing (Unprocessed Mash, Pellet, Double Pellet). Pelleted treatments were steam conditioned and extruded through a pellet die. Double Pellet treatments repeated this process. All treatments were ground to similar particle size and fed to ten replicate raised wire cages of 10 straight-run Hubbard $\mathrm{x}$ Cobb 500 broiler chicks for $18 \mathrm{~d}$. Broilers provided a Basal $+\mathrm{MBM}$ diet improved FCR $(\mathrm{P}=0.0046)$. Pelleting and Double Pelleting improved FCR compared to Unprocessed Mash $(\mathrm{P}=0.0003)$. Formulation and processing effects interacted to affect LWG, digestible lysine, methionine, threonine, and cysteine concentrations $(\mathrm{P}<0.05)$. Improvements to $\mathrm{LWG}$ were apparent only when Basal $+\mathrm{MBM}$ diets were thermally processed. Digestible amino acid concentration improved when Basal and Basal + MBM diets were thermally processed. However, digestible lysine and cysteine concentrations decreased when Basal + BBP were thermally processed. In vitro reactive lysine results did not support digestible lysine concentration results. Nutritional benefit or detriment of thermal processes associated with pelleting were dependent on diet formulation.

The objectives of the second study were to assess various commercial inorganic feed phosphates in diets that contained high fat distillers dried grains with solubles (DDGS) effect on feed manufacture variables. Diets with moderately high levels of corn DDGS are notoriously difficult to pellet due to their high fat and fiber content. Therefore the addition of inorganic phosphate feed ingredients, especially tricalcium phosphate has been anecdotally thought to improve feed manufacture and pellet quality of diets high in corn DDGS. Feed was manufactured on three separate days, each day denoting a replication of the experiment. Six experimental diets consisted of corn- and soybean meal-based diets without meat and bone meal were formulated to include either: 1) FP\&S Dicalcium Phosphorus (DCaP), 2) Nexfos, 3) Bolifor, 4)Defourinated Phosphorous, 5) Mixture (1/5 Bolifor, 1/5 MSP, 3/5 DCP), or 6) Bolifor + SiO2. The inclusion of Deflourinate Phosphorous demonstrated decreased hot pellet temperature, motor amperage and pellet quality while increasing production rate relative to the diet that included Bolifor + $\mathrm{SiO} 2(\mathrm{P}<0.05)$. It is thought that the improvements demonstrated for this product could be due to the physical aspects of the product. The inorganic feed phosphate ingredient that exhibited the densest and smallest particle size is Deflourinated Phosphorous. The small-diameter and highdensity particles of Deflourinated Phosphorous could of provided greater inertia within the die, thus enhancing die scouring. The use of Bolifor demonstrated a significantly increased hot pellet temperature, but maintained similar motor amperage and production rate relative to diets that included DCP or Nexfos. Majority of pellet quality variables showed that diets containing Bolifor or DCP were similar yet superior to the diet containing the inorganic feed phosphate ingredient Nexfos. 


\section{Acknowledgements}

I would first like to show gratitude to my advisor, Dr. Joseph Moritz. Due to his continued support and guidance I would not have had the many opportunities at hand. Through perseverance, drive, and constant encouragement I have been able conquer many obstacles at hand and I will be forever grateful. Next, I would like to thank my committee members, Dr. Janet Tou and Dr. Marie Krause for their continual support, guidance, and being phenomenal role model. I would also like to thank the WVU Animal Science farm staff and faculty for their assistance. I would like to extend further appreciation to my fellow lab mates, without their help, guidance, and support; I would not have been able to complete any projects. Thank you; John Boney, Brian Glover, Tori Homen, Lydia Crites, Heather Baldwin, and Talman Hylton. Lastly but not least, I would like to thank my parents, Cindy and Bart, my brother, Zachery, my grandparents, Wills and Judith, and a multitude of friends. Without their support and encouragement throughout this experience I would not have been able to reach this major milestone in my life. 


\section{TABLE OF CONTENTS}

$\begin{array}{lll}\text { ABSTRACT } & \text { ii }\end{array}$

ACKNOLEDGEMENTS

TABLE OF CONTENTS IV

LIST OF TABLES

KEY vii

CHAPTER 1 : LITERATURE REVIEW

DIET FORMULATION 1

ALTERNATIVE FEED SOURCES 2

INORGANIC PHOSPHOROUS SOURCES

$\begin{array}{ll}\text { FEED MANUFACTURING } & 6\end{array}$

BENEFICIAL EFFECTS OF FEED MANUFACTURING 8

DETRIMENTAL EFFECTS OF FEED MANUFACTURING 9

REFERENCES 11

CHAPTER 2 : THE EFFECTS OF DIET FORMULATION AND THERMAL PROCESSES ASSOCIATED WITH PELLETING ON 18-D BROILER PERFORMANCE AND DIGESTIBLE AMINO ACID CONCENTRATION. $\quad 19$

SUMMARY

DESCRIPTION OF PROBLEM 
MATERIALS AND METHODS

RESULT AND DISCUSSION

FEED MANUFACTURE

LIVE PERFORMANCE

DESCRIPTIVE FEED ANALYSIS

CONCLUSIONS AND APPLICATIONS

REFERENCES AND NOTES

TABLE 1. Basal, Basal + MBM, and Basal + BBP diet formulations with selected calculated and analyzed nutrients.

TABLE 2. Descriptive feed manufacture data associated with each treatment.

TABLE 3. D 1-18 broiler performance for each treatment and marginal means for each main effect.

TABLE 4. Digestible Amino Acid Concentration

TABLE 5. Descriptive Feed Analysis Data and mean data for the digestible lysine concentration for comparison.

CHAPTER 3 : THE EFFECTS OF VARIOUS ROCK PHOSPHATE FEED INGREDIENTS

ON FEED MANUFACTURE VARIABLES AND PELLET QUALITY

DESCRIPTION OF PROBLEM

MATERIALS AND METHODS

RESULT AND DISCUSSION

INORGANIC FEED PHOSPHATE 
TABLE 1. Descriptive data of inorganic feed phosphate ingredients.

TABLE 2. . Basal + Dicalcium P, Basal + Nexfos, Basal + Bolifor, Basal + Russian DFP, Basal + Mixture, and Basal + Bolifor \& SiO2 diet formulations with selected calculated and analyzed nutrients.

TABLE 3. Feed manufacture and pellet quality data associated with each inorganic feed phosphate treatment.

FIGURE 1. Magnification (5x) [13] of left to right Dicalcium Phosphorus, Nexfos, Bolifor, Russian DFP, and Mixture (1/5 Bolifor, 1/5 MSP, 3/5 DCP).

CURRICULUM VITAE

\section{LIST OF TABLES}

\section{CHAPTER 2}

Table 1. Basal, Basal + MBM, and Basal + BBP diet formulations with selected calculated and analyzed nutrients.

Table 2. Descriptive feed manufacture data associated with each treatment.

Table 3. D 1-18 broiler performance for each treatment and marginal means for each main effect. Table 4. Digestible Amino Acid Concentration

Table 5. Descriptive Feed Analysis Data and mean data for the digestible lysine concentration for comparison.

\section{CHAPTER 3}

Table 1. Descriptive data of inorganic feed phosphate ingredients.

Table 2. . Basal + Dicalcium P, Basal + Nexfos, Basal + Bolifor, Basal + Russian DFP, Basal + Mixture, and Basal + Bolifor \& SiO2 diet formulations with selected calculated and analyzed nutrients.

Table 3. Feed manufacture and pellet quality data associated with each inorganic feed phosphate treatment.

Figure 1. Magnification (5x) [13] of left to right Dicalcium Phosphorus, Nexfos, Bolifor, Russian DFP, and Mixture (1/5 Bolifor, 1/5 MSP, 3/5 DCP). 


\section{CHAPTER 1}

1. Distiller Dried Grains with Solubles- DDGS

2. Bakery By-Product -BBP

3. Meat and Bone Meal -MBM

4. Live Weight Gain- LWG

5. Feed Conversion Ratio - FCR

6. Non Starch Polysaccharides - NSP

7.True Amino Acid Digestibility - TAAD

\section{CHAPTER 2}

1. Soybean Meal - SBM

2. Distillers Dried Grains with Solubles - DDGS

3. Meat and Bone Meal - MBM

4. Bakery By-Product - BBP

5. Feed Conversion Ratio - FCR

6. Live Weight Gain - LWG

7. Hot Pellet Temperature - HPT

8. Pellet Durability Index - PDI

9. Titanium Dioxide - $\mathrm{TiO}_{2}$

10. Digestible Amino Acid Concentration - DAAC

11. Total Amino Acid - TAA

12. Apparent Ileal Digestibility - AID

\section{CHAPTER 3}

1. Distillers Dried Grains with Solubles - DDGS

2. Dicalcium Phosphorous - DCP

3. Monosodium Phosphorous - MSP

4. Silicon Dioxide - $\mathrm{SiO}_{2}$

5. Hot Pellet Temperature - HPT

6. Conditioner Electrical Energy - CEE

7. Pellet Mill Electrical Energy - PMEE

8. New Holmen Pellet Tester - NHPT

9. Pellet Durability Index - PDI

10. Modified Pellet Durability Index - MPDI 


\section{CHAPTER 1: LITERATURE REVIEW}

\section{Diet Formulation}

Formulation of balanced diets is fundamental to economical poultry production. Formulating a diet depends on a knowledge of nutrient requirements for poultry and the nutritional attributes of nutrient sources [1]. Poultry diets are composed primarily of a mixture of several feedstuffs such as cereal grains, soybean meal, animal by-product meals, fats, and vitamin and mineral premixes [1]. These feedstuffs, together with water, provide the energy and nutrients that are essential for the bird's growth, reproduction, and health, namely proteins and amino acids, carbohydrates, fats, minerals, and vitamins [1]. The energy necessary for maintaining the bird's general metabolism and for producing meat and eggs is provided by the energy-yielding dietary components, primarily carbohydrates and fats, but also protein [1].

Energy is not a nutrient but a property of energy-yielding nutrients when they are oxidized during metabolism. The energy value of a feed ingredient or of a diet can be expressed in several ways [1]. A common expression of energy value in a diet formulation is metabolizable energy (kcal or MJ ME/kg feed) [2].

Dietary requirements for protein are actually requirements for the amino acids contained in multiple components of the diet. Amino acids obtained from dietary protein are used by poultry to fulfill a diversity of functions [1]. For example, amino acids, as proteins, are primary constituents of structural and protective tissues, such as skin, feathers, bone matrix, and ligaments, as well as of the soft tissues, including organs and muscles [1]. Also, amino acids and small peptides resulting from digestion and absorption may serve a variety of metabolic functions and as precursors of many important non-protein body constituents [1]. Because body proteins are in a dynamic state, with synthesis and degradation occurring continuously, an 
adequate intake of dietary amino acids is required [1]. If dietary protein (amino acids) is inadequate, there is a reduction or cessation of growth or productivity and a withdrawal of protein from less vital body tissues to maintain the functions of more vital tissues. Digestible amino acids are often included for first limiting amino acid, methionine, and most of the essential amino acids [2]. In the instance of essential amino acids, greater dietary concentrations may be required to optimize efficiency of feed utilization [1].

The dietary requirements for meat-type chickens vary according to whether birds are broilers being started and grown for market, broiler breeder pullets and hens, or broiler breeder males [1]. Therefore, the nutrient composition of the diet is adequately prepared for a specific class of poultry. Furthermore, nutrient requirements may vary according to the criterion of adequacy of certain feed ingredients.

\section{Alternative Feed Sources}

Feed cost accounts for 60 to $75 \%$ of total production cost in poultry production [3]. Therefore it is important for poultry nutritionist to focus on a method of providing the most cost efficient, yet performance promoting diet for the chicken [3]. With the cost of conventional feed ingredients constantly rising, the utilization of alternative feed ingredients may be beneficial to a least-cost efficient diet formulation. Prior to formulating a diet utilizing alternative ingredients it is prudent to have a proper understanding of the alternative feed ingredient and the nutrient availability of the ingredient.

A current alternative feed source that is highly utilized in the poultry industry is corn Distiller Dried Grains with Solubles (DDGS) [4]. Ethanol production yields the by-product DDGS, this production consist of a conventional dry grinding process [4]. Corn is ground and mixed with water to produce slurry, the slurry is then cooked causing a liquefaction of the 
starches present in the slurry. The liquefaction process of the slurry yields a product which undergoes fermentation to produce ethanol. The remaining nonfermentables (germ, fiber and protein) are recovered together at the end of the dry grind process as an animal feed by-product called DDGS [5]. Through the several functional steps of ethanol production, variability could occur in the by-product. Therefore lacking consistency of the production could lead to inconsistent nutrient content and digestibility of the by-product [6]. Several experiments were conducted by Parson et al. to evaluate the variation in nutrient content and digestibility among different commercial samples of DDGS [7]. This evaluation exhibited substantial variation of nutrient composition among DDGS samples, with the greatest variation being found in digestibility of lysine [7]. It is thought that the amino acid lysine may be damaged if excessive heating that is used during the drying process of DDGS, which could lead to a low digestibility of lysine [8]. An experiment conducted by Almeida et al. evaluated the effects of heat treatment of DDGS on the standardized ileal digestibility of amino acids. This experiment identified that the concentration of total lysine, was $0.82 \%$ in non-autoclaved DDGS and $0.65,0.73$, and $0.68 \%$ in the DDGS that was autoclaved for 10,20, and $30 \mathrm{~min}$, respectively [9]. These results indicated that the digestibility of lysine was reduced by heat damage than the digestibility of other amino acids. Therefore varying nutrient content, specifically varying lysine availability; could lead to disadvantages in performance for broilers, it is important to reevaluate the content of nutrients, availability and variation in digestibility prior to formulation.

Another alternative feed source currently utilized in the poultry industry is bakery byproduct meal (BBP). The alternative ingredient is a high-energy, nutrient dense, highly palatable dried component for livestock feed, which has a greater nutrient value than corn dependent on sourcing of the feed ingredient [10]. The production of BBP consists of a dried blend of various 
unsaleable products produced by the bakerage industry, including bread, cakes, cookies, potato chips, and similar items. The various products are collected, ground, mixed, and dried to a moisture content of approximately $10 \%$ [11]. Studies performed by Dale et al. found that samples of BBP obtained from different plants varied widely in terms of their nutrient and ME contents [12]. It has also been reported that digestibility of lysine in BBPs may be reduced, probably by the development of Maillard linkages during the cooking process [14-16].

Furthermore, Saleh et al. demonstrated that variation of the sourced ingredient could lead to variation in available lysine content of the ingredient. Saleh et al. found when BBP was utilized in a complete feed diet reduction of lysine availability was noted at 0.04 to $0.06 \%$ [17].

Therefore, if diets are marginal in lysine content, one should consider an adjustment in the lysine value assigned to BBP to correct for this reduction. Therefore, successful utilization of BBP is contingent upon the quality of the feed ingredient.

The most common animal byproduct used in broiler diets is meat and bone meal. These feedstuffs contain high protein levels and may partially replace the protein component of poultry diets. In addition of being a protein source, meat and bone meal is also a significant source of totally available calcium and phosphorous [18]. Broiler performance result when animal byproducts are fed may be variable as a function of raw material type and quality, processing temperature, use of antioxidants to maintain their quality, contamination by pathogenic microorganisms, high polyamine content, amino acid unbalance, nutrient content and digestibility, and storage conditions [19]. Previous research by Parsons et. al demonstrated that various analyzed meat and bone meals contain various levels of non-essential amino acids, the presence of non-essential amino acids in the diet ensures the efficient use of the essential amino acids [20]. Furthermore, Corzo et al. in evaluated individual and combined responses of broiler 
chicks to non-essential crystalline amino acid supplementation of a low crude protein starter diet compared to a control starter diet with an adequate level of crude protein [21]. This experiment identified that at day 13 of the study birds that consumed the control diet had similar body weight gain to the diet containing a low crude protein content with all non-essential amino acids supplemented [21]. At the termination of the study it was concluded that diets with the supplementation of the non-essential amino acids glycine and leucine to a low crude protein diet had similar feed conversion ratio compared to the chicks that consumed the control diet [21]. In conclusion Corzo et. al. speculated that supplementation of some non-essential amino acids may have showed partial or intermediate benefits [21]. These results coincide with the speculation of Wu et al in 2012. Wu et al speculated that if an excess of non-essential amino acids are pronounced in the diet the amino acids will undergo deamination which will allow for cells to generate an abundance of energy which can be utilized for enhancing growth and performance [22]. Therefore, the excess of non-essential amino acids may allow for the bird to have improved performance. To further support the variation in the nutrient content of meat and bone meal research performed by Martosiswoyo and Jensen suggest that the NRC table underestimates the ME value assigned to MBM [23]. Martosiswoyo and Jensen evaluated the performance and abdominal fat content of broiler chicks fed diets formulated with MBM that was assigned with different ME values [23]. The results from the Martosiswoyo and Jensen study indicated that when female broilers consumed diets with the highest ME MBM of 2,500 kcal $/ \mathrm{kg}$, the birds had improved feed efficiency compared to birds fed diets with decreased ME MBM [23].

\section{Inorganic Phosphorus Sources}

The addition of inorganic phosphorous sources to the feed may improve the decreased quality of the pellet. The addition of inorganic phosphorus feed sources can also improve the 
availability of phosphorus in the diet. In diets of non-rumminant animals, such as broilers, the challenge in phosphorous nutrition is dependent on the availability of the phosphorous in the diet [24]. The phosphorous found in plant sources is present in a different form, where the phosphorous is attached to organic molecules like phospholipids and proteins [24]. Most phosphorous that is supplemented in the diet through plant material is present as a phytic acid molecule [25]. The phytic acid phosphorous found in plants is inconsistent because availability of phosphorus to poultry is 0 to $50 \%$ [25]. Therefore, to meet the requirement of phosphorous of the bird, inorganic P must be added to the diet.

Most commercial poultry diets are notorious for being deficient in nonphytate phosphorus, therefore the supplementation of inorganic feed phosphate will allow for the requirements to be met. However, inorganic feed phosphate sources are highly variable in regards to sourcing, manufacturing techniques, nutrient content, particle size, and density of the ingredient [26]. Accompanied with variations of the feed ingredient, information regarding the effects of inorganic feed phosphates on pelleting parameters are not well-known.

Inorganic feed phosphates have abrasive properties that may scour the pellet die and negatively affect feed production rate, energy use of the pellet mill, or a combination of the factors [27]. However, it has been proposed that inorganic feed phosphate particle can maintain a clean die due to its ability to dislodge residual feed that may adhere to the inner die surface [27-29]. Therefore, it is prudent to have a complete understanding of inorganic feed phosphate sources and their effects to feed manufacturing.

\section{Feed Manufacturing}

The pelleting process combines saturated steam, shear forces, and die residence time to alter ingredient conformation and ultimately the physical form of feed. Many studies have indicated 
that feeding pellets improves broiler performance relative to mash due to improved physical form that enables greater intake, weight gain, and lower maintenance energy requirements associated with feeding [30-37]. However, the effect of thermal processes of pelleting on nutrient availability are not well understood. Plavnik and coauthors reported that pelleted feed only improved broiler live weight gain (LWG) and feed conversion ratio (FCR) when pellets remained intact since ground pellets did not improve performance [38]. Loar and coauthors found that conditioning corn and soybean meal based diets above $74^{\circ} \mathrm{C}$ increased broiler feed conversion ratio and decreased amino acid digestibility [39]. However, Lamp et. al. [40] reported that feeding hulled barley based diets in ground pellet form improved broiler intake and gain relative to similarly formulated unprocessed mash diets. Moreover, techniques should be monitored so that nutrient availability is maintained, due to the shear forces, heat, die residence time, and water may result in partial protein denaturation [41] and may result in changes in protein availability to a non-ruminant animal [43]. Standard feed manufacture conditions and/or diet formulations do not exist and as such, past literature has utilized a variety of conditions without consistent results on bird performance or nutrient availability [44]. Therefore, feed form benefits may compensate for decreased nutrient availability [45], having a complete understanding of the interactions among feed ingredients or the effects of thermal processing on nutrient quality and subsequent broiler performance must be further examined.

A technique that is utilized to accomplish the pelletization process is known as steam conditioning. This process allows for the physical properties of mash feed to be modified into a pelleted form [46]. Conditioning usually involves the addition of steam to the mash, the primary purpose of this process is to improve the quality of pellet and/or the throughput of the pellet mill [46]. Research presented by colleagues from the lab groups reported pellet quality improvements 
are significantly higher as conditioning temperatures are increased [47]. Furthermore, Cutlip et. al. demonstrated increased pellet durability followed my increased modified pellet durability as the diets were conditioned at higher temperatures relative to diets conditioned at lower temperatures [48]. Although improvements in pellet quality are highly noted when coupled with increased conditioning temperatures, a heat threshold must be considered for the nutrients in the diet undergoing the thermal processing. Due to high temperatures the nutrient availability may be compromised which could lead to anti nutritive factors to occur [48].

\section{Beneficial Effects of Feed Manufacturing}

Non-starch polysaccharides (NSP) cannot be digested by mammalian enzymes due to the structural arrangement of the NSPs [49]. Past research has identified that processing technologies may alter the physicochemical properties of non-starch polysaccharides [50]. Furthermore, thermal processes can break weak bond between polysaccharides and glycosidic linkages within polysaccharides. Therefore in starch-rich products, heating, particularly under moist conditions, may cause starch gelatinization [51-54]. This causes the cell to swell and break, thereby increasing the surface area of the cell and disruption of the cellular integrity, which can lead to increased utilization of the nutrients found in the grain [51-54]. A study performed by Saunders et al. evaluated the biological availability of wheat bran nutrients for unprocessed feed and pelleted feed by microscopically analyzing the aleurone layer of the cell walls, which encapsulates significant amounts of nutritive components within the cereal grain [49]. The microscopic analysis identified that as the feed underwent thermal processing a significant amount of cell wall breakage to the aleurone layer when compared to unprocessed mash. Saunders et al. speculated that the damage of the aleurone cell wall can improve the utilization of nutrients within the cereal grain [49]. Furthermore, a study conducted by Anguita 
et al. identified that the effects of technological processing, such as extrusion, on maize had improved hydrolysis of starches found in the grain [54]. These results were identified by evaluating the starch hydrolysis, solubilization of NSP and the physiochemical properties. The solubility of maize once undergoing gastic digestion demonstrated improved solubility of the extruded ingredient when compared to the raw ingredient [54]. The improvement of solubility is thought improve the utilization of the nutrients in the cereal grain.

\section{Detrimental Effects of Feed Manufacturing}

A major factor that is seen in thermal processed feed is the Maillard reaction, the high temperatures and low moisture used in pellet formation favors the reaction [41]. The Maillard reaction, or non-enzymatic browning reaction, between reducing sugars and amino acid, is known to cause deterioration of food quality during processing and storage. Maillard products may impair nutritional value of the feed due to reduced utilization of proteins $[48,41,55]$. The reduced utilization of protein is demonstrated in the presence of heat and moisture, free aldehyde groups (e.g. glucose) and free amine groups (e.g. epsilon-amino group of lysine) yield melanoides that darken feed and increase digesta viscosity [56,57]. Increasing evidence shows that these compounds formed under mild conditions substantially reduce the availability of amino acids and proteins [58]. This is further demonstrated by research conducted by Papadopoulos which found that high processing temperature are associated with the degradation of cysteine which is the most heat-labile amino acid, followed by lysine, then arginine, threonine, and serine [41]. M.Tanaka et al also reported decreased nutritional value of feed that undergoes a certain extent of thermal processing. This experiment demonstrated that as feed underwent harsh thermal processing the prevalence of the Maillard Reaction occurred. Formation of the Maillard Reaction could account for the loss of biological available lysine, which could lead to a 
reduction in performance of the bird [59]. Boney and Moritz found that conditioning temperature, in general, affected True Amino Acid Digestibility (TAAD) of multiple tested amino acids. More specifically leucine, valine, isoleucine, alanine, and aspartic acid decreased in digestibility when conditioned at $91{ }^{\circ} \mathrm{C}[60]$. Through this evaluation Boney and Moritz concluded that steam conditioning at high temperatures produces conformational changes in proteins and amino acids that may affect the digestibility of proteins and amino acids [60]. Furthermore, Amerah et al. reported that higher feed processing temperatures can affect nutrient availability through protein denaturation, maillard complexing, and loss of feed additives such as synthetic amino acids [61]. Loar et al. reported similar results of decreased TAAD for methionine, isoleucine, and proline when steam conditioning temperatures increased from $74{ }^{\circ} \mathrm{C}$ to either 85 or $96^{\circ} \mathrm{C}[62]$. 


\section{REFERENCES AND NOTES}

1. Subcommittee on Poultry Nutrition Staff, Committee. Nutrient Requirements of Poultry: Ninth Revised Edition, 1994. National Academies Press, 1993.

2. "Feed Formulation." Poultry Hub, www.poultryhub.org/nutrition/feed-formulation/.

3. Jurgens, et al. "Poultry Nutrition and Feeding." Animal Nutrition Handbook, 2014, pp. $410-424$.

4. "DDGS." U.S. Grains Council, 25 Apr. 2017, www.grains.org/buyingselling/ddgs

5. Singh, V., C. Parsons, and J. Pettigrew. 2007. Process and engineering effects on DDGS products - present and future. Pages 82-96 in Proc. 5th Mid-Atlantic Nutr. Conf., Timonium, MD. Univ. Maryland, College Park.

6. 'Nutrient Composition and Digestibility of DDGS: Variability and In Vitro Measurement." U.S. Grains Council, 22 Apr. 2014, www.grains.org/buyingselling/ddgs/handbook/20140422/nutrient-composition-anddigestibility-ddgs-variability-and.

7. Parsons, C. M., et al. "Multi-State Poultry Nutrition and Feeding Conference (2006) NUTRITIONAL VALUE OF CONVENTIONAL AND MODIFIED DDGS FOR POULTRY Summary.

8. Stein, H. H. 2006. "DDGS: Energy and nutrient content and digestibility". Department of Animal Science. University of Illinois.

9. Lahaye, Ludovic et al. Technological processes of feed manufacturing affect protein endogenous losses and amino acid availability for body protein deposition in pigs. Animal Feed Science and Technology, Volume 113, Issue 1, 141-156. 
10. Waldroup, P.W., D.L. Whelchel, and Z.B. Johnson, 1982. Variation in nutrient content of samples of dried bakery product. Anim. Feed Sci. Tech. 7:419-421.

11. Dale, N.M., 1989. Predicting the energy content of dried bakery product. Cooperative Extension Service Poultly Nutrition Short Communication No. 4, The University of Georgia, Athens, GA.

12. Dale, N. M., 1986. Energy and nutrient content of dried bakery product and crab meal. Poultry Sci. 65:(Suppl.1):163.

13. 14. Harrison, M.D., M.E Jackson, D.G. McLaren, and C.M. Parsons, 1990. A direct comparison of true amino acid digestibility determined with poultry and apparent amino acid digestibility determined with swine. Poultry Sci. 69(Suppl):60.

14. Parsons, C.M., 1991. Amino acid digestibilities for poultry: Feedstuff evaluation and requirements. biokyowa Technical Review-1, Biokym, Inc., Chesterfield, MO.

15. Anonymous, 1993. Rhodirnet"' Nutrition Guide, 2nd Edition. Rhone-Poulenc Animal Nutrition, 92164 Antony Cedex, France.

16. Dale, N.M., 1992. Pelleting effects on lysine bioavailability in diets containing dried bakery product. J. Appl. Poultry Res. 1:84-87.

17. Saleh, E. A., S. E. Watkins, and P. W. Waldroup. 1996. "High-Level Usage of Dried Bakery Product in Broiler Diets 1 | The Journal of Applied Poultry Research | Oxford Academic." OUP Academic. Oxford University Press. Web.

18. Caires, CMI, Fernandes, EA, Fagundes, NS, Carvalho, AP, Maciel, MP, \& Oliveira, BR. (2010). The use of animal byproducts in broiler feeds: use of animal co-products in broilers diets. Revista Brasileira de Ciência Avícola, 12(1), 41-46. 
19. Bellaver C. Ingredientes de origem animal destinado à fabricação de rações. Anais do Simpósio Sobre Ingredientes na Alimentação Animal; 2001; Campinas, São Paulo. Brasil.

20. Parsons, C. M., F. Castanon, and Y. Han. 1997. Protein and amino acid quality of meat and bone meal. Poult. Sci. $76: 361-368$

21. Corzo, A., et al. "Response of Broiler Chicks to Essential and Non-Essential Amino Acid Supplementation of Low Crude Protein Diets." Animal Feed Science and Technology, vol. 118 , no. 3-4, 2005, pp. 319-327., doi:10.1016/j.anifeedsci.2004.11.007.

22. Wu, Guoyoa, Zhenlong Wu, Zhaolai Dai, Ying Yang, Weiwei Wang, Chuang Liu, Bin Wang, Junjun Wang, and Yulong Yin. "Dietary Requirements of "nutritionally nonessential Amino Acids" by Animals and Humans." Springer 44 (2012): 1107-113. Web.

23. A.W. Martosiswoyo, 1. S. Jensen; Effect of Formulating Diets Using Differing Meat and Bone Meal Energy Data on Broiler Performance and Abdominal Fat Content. Poult Sci 1988; 67 (2): 294-299.

24. C.A. Fritts and P.W. Waldroup. 2006. Modified Phosphorus Program for Broilers Based on Commercial Feeding Intervals to Sustain Live Performance and Reduce Total and Water-Soluble Phosphorus in Litter. J. Appl. Poult. Res. 15:207-218

25. Common Feed Ingredients in Poultry Diets. July 03, 2013. www.extension.org

26. Lima F. R. Mendonca C. X. Jr. Alvarez J. C. Ratti G. Lenharo S. L. R. Kahn H. Garzillo J. M. F. 1995. Chemical and physical evaluations of commercial dicalcium phosphates as sources of biologically available phosphorus for broiler chicks. Poult. Sci. 74:16591670. 
27. Behnke K. C. 1981. Pellet mill performance as affected by mineral source. Feedstuffs $53: 34-36$

28. Verner W. A. 1988. Phosphates in pelleting: Best cost vs. least cost. Feed Manage. 39:56- 58 .

29. Lowe R. Zwart S. 2007. Does the choice of feed phosphate affect pelleting behavior? Feed Compound. 27:20-23.

30. Behnke, K. C. 1996. Feed manufacturing technology: Current issues and challenges. Anim. Feed Sci. Technol. 62:49-57.

31. Jensen, L. S., L. H. Merrill, C. V. Reddy, and J. Mc-Ginnis. 1962. Observations on eating patterns and rate of food passage of birds fed pelleted and unpelleted diets. Poult. Sci. 41:1414-1419.

32. Hott, J. M., N. P. Buchanan, S. E. Cutlip, and J. S. Moritz. 2008. The effect of moisture addition with a mold inhibitor on pellet quality, feed manufacture, and broiler performance. J. Appl. Poult. Res. 17:262-271.

33. Moritz, J. S., R. S. Beyer, K. J. Wilson, K. R. Cramer, L. J. McKinney, and F. J. Fairchild. 2001. Effect of moisture addition at the mixer to a corn-soybean based diet on broiler performance. J. Appl. Poult. Res. 10:347-353.

34. Nir, I., Y. Twina, E. Grossman, and Z. Nitsan. 1994. Quantitative effects of pelleting on performance, gastrointestinal tract and behavior of meat-type chickens. Br. Poult. Sci. 35:589-602.

35. Behnke, K. C. 1994. Factors affecting pellet quality. Pages 44-54 in Proc. Maryland Nutr. Conf., College Park, MD. Maryland Feed Ind. Counc. and Univ. Maryland, College Park. 
36. Scheideler, S. E. 1991. Pelleting is important for broilers. Pages 1-7 in Proc. 18th Annu. Carolina Poult. Nutr. Conf., Charlotte, NC. North Carolina State Univ., Raleigh.

37. Silversides, F. G. and Bedfor, M. R. 1999. Effect of pelleting temperature on the recovery and efficacy of xylanase enzyme in wheat-based diets. Poult. Sci. 78: 11841190.

38. Plavnik, I. , E. Wax, D. Sklan, and S. Hurwitz. 1997. The response of broiler chickens and turkey poults to steam-pelleted diets supplemented with fat or carbohydrates. Poult. Sci. 76:1006-1013.

39. R. E. Loar, II, K. G. S. Wamsley, A. Evans, J. S. Moritz, A. Corzo. 2014. Effects of varying conditioning temperature and mixer-added fat on feed manufacturing efficiency, 28- to 42-day broiler performance, early skeletal effect, and true amino acid digestibility. J Appl. Poult. Res. 23: 3, pp 444-455.

40. A. E. Lamp, A. M. Evans, J. S. Moritz. 2015. The effects of pelleting and glucanase supplementation in hulled barley based diets on feed manufacture, broiler performance, and digesta viscosity. J Appl. Poult. Res. 24: 3, pp 295-303.

41. Papadopoulos, M. C. 1989. Effect of processing on high-protein feedstuffs: A review. Biol. Wastes 29:123- 138.

42. Marsmana, G.J.P., H. Gruppen, D.J. van Zuillichem, J.W. Resink, and A.G.J. Voragen. 1995. The influence of screw configuration on the in vitro digestibility and protein solubility of soybean and rapeseed meals. J. of Food Eng. 26 (1): $13-28$.

43. Thomas, M., D. J. van Zuilichem, and A. F. B. Van der Poel. 1997. Physical quality of pelleted animal feed. 2. Contribution of processes and its conditions. Anim. Feed Sci. Tech. 64:173-192. 
44. C. K. Gehring, K. G. S. Lilly, L. K. Shires, K. R. Beaman, S. A. Loop, J. S. Moritz. 2011. Increasing mixer-added fat reduces the electrical energy required for pelleting and improves exogenous enzyme efficacy for broilers. J Appl. Poult. Res. 20 (1): 75-89.

45. Silversides, F. G. and Bedford, M. R. 1999. Effect of pelleting temperature on the recovery and efficacy of xylanase enzyme in wheat-based diets. Poultry Science 78: 1184-1190.

46. Schofield, Eileen K. Feed Manufacturing Technology V. American Feed Industry Association, 2005.

47. Loar II, R.E., K.G.S. Wamsley, A. Evans, J.S. Moritz, and A. Corzo, A. 2014. Effects of varying conditioning temperature and mixer-added fat on feed manufacture efficiency, 28-to-42-day broiler performance, early skeletal effect, and true amino acid digestibility. J. Appl. Poult. Res. 23:444-455.

48. Cutlip, S.E., J.M. Hott, N.P. Buchanan, A.L. Rack, J.D. Latshaw, and J.S. Moritz. 2008. The Effect of Steam-Conditioning Practices on Pellet Quality and Growing Broiler Nutritional Values. J. Appl. Poult. Res. 17:249-261.

49. Saunders, R. M., Walker, H. G. and Kohler, G. O. 1969. Aleurone cells and the digestibility of wheat mill feeds. Poultry Science 48: 1497-1503.

50. Bedford, M. R. 2002. The role of carbohydrases in feedstuff digestion, in: McNab, J. M. and Boorman, K. N. (Eds.), Poultry Feedstuffs: Supply, Composition and Nutritive Value, Wallingford, CAB International, pp: 319-336.

51. Choct, M. and Annison, G. 1992. The inhibition of nutrient digestion by wheat pentosans. British Journal of Nutrition 67:123-132 
52. S. de Vries, A.M. Pustjens, H.A. Schols, W.H. Hendriks, W.J.J. Gerrits, Improving digestive utilization of fiber-rich feedstuffs in pigs and poultry by processing and enzyme technologies: A review, Animal Feed Science and Technology, Volume 178, Issue 3, 2012, Pages 123-138, ISSN 0377-8401.

53. McDougall, G.J., Morrison, I.M., Stewart, D., Hillman, J.R., 1996. Plant cell walls as dietary fibre: range, structure, processing and function. J. Sci. Food Agric. 70, 133-150.

54. M. Anguita, J. Gasa, S.M. Martín-Orúe, J.F. Pérez, Study of the effect of technological processes on starch hydrolysis, non-starch polysaccharides solubilization and physicochemical properties of different ingredients using a two-step system, Animal Feed Science and Technology, Volume 129, Issue 1, 2006, Pages 99-115, ISSN 0377 8401.

55. Pickford, J.R. 1992. Effects of processing on the stability of heat labile nutrients in animal feeds. Pages $177-192$ in: Recent Advances in Animal Nutrition. P. C. Garnsworthy, W. Haresign, D.J.A. Cole, ed. Butterworth-Heinemann, Oxford, U.K.

56. Hendricks, W.H., P.J. Maughan, H. Boer, and A.F.B. van der Poel. 1994. Effects of extrusion on the dye-binding, fluorodinitrobenzene-reactive and total lysine content of soyabean meal and peas. Ani. Feed Sci. and Tech. 48: $99-109$.

57. Camire, M. E., Camire, A. and Krumhar. K. 1990. Chemical and nutritional changes in food during extrusion. Critical Reviews in Food Science and Nutrition. 29: 35- 57.

58. Pickford, J. R. 1992. Effects of processing on the stability of heat labile nutrients in animal feeds, in Garnsworthy, P. C., Haresign, W. and Cole, D. J. A. (Eds.), Recent Advances in Animal Nutrition, Butterworth Heinemann, Oxford, UK. pp: 177-192. 
59. Tanaka M., Kimiagar M., Lee TC., Chichester C.O. 1977. Effect of Maillard Browning Reaction on Nutritional Quality of Protein. In: Friedman M. (eds) Protein Crosslinking. Advances in Experimental Medicine and Biology, vol 86.

60. Boney J. W. and Moritz J. S. 2017. The effects of Spirulina algae inclusion and conditioning temperature on feed manufacture, pellet quality, and true amino acid digestibility. Animal Feed Science and Technology. Elsevier, 09 Dec. 2016. Web.

61. A.M. Amerah, C. Gilbert, P.H. Simmins, V.RavindranInfluence of feed processing on the efficacy of exogenous enzymes in broiler diets. World's Poult. Sci. J., 67 (2011), pp. 2946

62. R.E. Loar II, K.G.S. Wamsley, A. Evans, J.S. Moritz, A. Corzo. Effects of varying conditioning temperature and mixer-added fat on feed manufacture efficiency, 28-to-42day broiler performance, early skeletal effect, and true amino acid digestibility. J. Appl. Poult Res., 23 (2014), pp. 444-455 
CHAPTER 2: The effects of diet formulation and thermal processes associated with pelleting on 18-d broiler performance and digestible amino acid concentration.

\author{
A. N. Bergeron and J. S. Moritz \\ Division of Animal and Nutritional Sciences, West Virginia University, Morgantown, West \\ Virginia, 26506
}

Phone: 304-293-1911

Fax: 304-293-2232 
SUMMARY The objectives of the study were to assess performance and digestible amino acid concentration of diets fed to broilers that differed in formulation and degree of thermal processing. Basal diets were corn, SBM, and DDGS based and formulations were balanced to be similar in calculated metabolizable energy and digestible amino acids. Treatments were arranged in a 3 × 3 factorial that varied in diet formulation (Basal, Basal + Meat and Bone Meal (MBM), and Basal + Bakery Byproduct (BBP)) and degree of thermal processing (Unprocessed Mash, Pellet, Double Pellet). Pelleted treatments were steam conditioned and extruded through a pellet die. Double Pellet treatments repeated this process. All treatments were ground to similar particle size and fed to ten replicate raised wire cages of 10 straight-run Hubbard x Cobb 500 broiler chicks for $18 \mathrm{~d}$. Broilers provided a Basal + MBM diet improved FCR $(\mathrm{P}=0.0046)$. Pelleting and Double Pelleting improved FCR compared to Unprocessed Mash ( $\mathrm{P}=0.0003)$. Formulation and processing effects interacted to affect LWG, digestible lysine, methionine, threonine, and cysteine concentrations $(P<0.05)$. Improvements to LWG were apparent only when Basal + MBM diets were thermally processed. Digestible amino acid concentration improved when Basal and Basal + MBM diets were thermally processed. However, digestible lysine and cysteine concentrations decreased when Basal + BBP were thermally processed. In vitro available lysine results did not support digestible lysine concentration results. Thermal processing decreased trypsin inhibitor complex activity for each formulation. Nutritional benefit or detriment of thermal processes associated with pelleting were dependent on diet formulation.

Key Words: thermal processing, diet formulation, amino acid digestibility, performance 


\section{DESCRIPTION OF PROBLEM}

Commercial broilers are almost exclusively fed pelleted diets. Feed and feed manufacture comprise the bulk of broiler production cost. The use of low-cost ingredients with high nutrient availability are critical to broiler production economics [1]. Current least-cost feed formulation utilizes nutrient availability of ingredients; however, the effects of thermal processing on nutrient availability are not typically considered [2].

The pelleting process combines saturated steam, shear forces, and die residence time to alter ingredient conformation and ultimately the physical form of feed. Many studies have indicated that feeding pellets improves broiler performance relative to mash due to improved physical form that enables greater intake, weight gain, and lower maintenance energy requirements associated with feeding behavior [3-10]. However, the effect of thermal processes of pelleting on nutrient availability are not well understood. Plavnik and coauthors reported that pelleted feed only improved broiler live weight gain (LWG) and feed conversion ratio (FCR) when pellets remained intact since ground pellets did not improve performance [11]. Loar and coauthors found that conditioning corn and soybean meal based diets above $74^{\circ} \mathrm{C}$ increased broiler FCR and decreased amino acid digestibility [12]. However, Lamp et. al. [13] reported that feeding hulled barley based diets in ground pellet form improved broiler intake and gain relative to similarly formulated unprocessed mash diets.

Thermal processes associated with pelleting have been broadly speculated to solubilize dietary fiber and alter the conformation of proteins and starches [14]. Conformational changes of ingredients may improve enzyme access when diets are fed or decrease nutrient availability when new products are formed such as through the Maillard reaction [15-17]. 
The current study explored three different diet formulations (Basal, Basal + Meat and Bone Meal (MBM), and Basal + Bakery Byproduct (BBP)) and degrees of thermal processing (Unprocessed Mash, Pellet, Double Pellet). The objectives were to assess performance and digestible amino acid concentration of diets fed to broilers that differed in formulation and degree of thermal processing.

\section{MATERIALS AND METHODS}

\section{Feed Manufacture}

All feed was manufactured at the West Virginia University Pilot Feed Mill. Diets were formulated to be isocaloric and similar to Agristat values [18] and at $90 \%$ of the digestible lysine recommendations of Tillman and Dozier for 8 to $14 \mathrm{~d}$ broilers [19]. Digestible amino acid to digestible lysine ratios followed further recommendations of this communication [19]. Digestible lysine was decreased in order to increase bird performance sensitivity to a change in lysine availability due to thermal processing. Dietary formulations consisted of a basal formulation that included corn, soybean meal, and 5\% DDGS, Basal + 5\% MBM, or Basal $+7.5 \%$ BBP (Table 1 ). The DDGS was from ethanol production and not de-oiled [20]. The MBM was porcine derived [20] and the BBP was described by the manufacturer as a cookie meal [21]. Soybean oil comprised the added fat and was added at the mixer.

A master batch was mixed containing common ingredients, divided into three allotments, and supplemented with additional ingredients to create treatment formulations. The three diet formulations were provided either as an Unprocessed Mash that was not thermally processed; a Pellet that was conditioned using a short-term conditioner $(0.31 \times 1.30 \mathrm{~m}, 10$-s retention time $)$ at $90^{\circ} \mathrm{C}$, extruded through a 4.7 (diameter) x $44 \mathrm{~mm}$ (effective thickness) pellet die without relief using a 40HP California Pellet Mill [22], cooled, and ground through a roller mill; and a Double 
Pellet that went through the same process to generate Pellet twice with the exception of an $82^{\circ} \mathrm{C}$ conditioning temperature during the second conditioning. The lower second conditioning was necessary due to elevated moisture content of the feed from initial conditioning and potential for pellet die slippage during second pelleting. Pellet grinding with a roller mill was conducted to standardize feed form among treatments. Feed was stored in a dehumidified room prior to feeding in order to standardize moisture content among treatments.

\section{Feed Analysis}

Average hot pellet temperature (HPT), pellet durability index (PDI), and particle size were recorded as descriptive data during and post manufacture (Table 2). Measures of HPT were obtained by placing an insulated container under the pellet mill chute, catching hot pellets, immediately closing the lid, and use of a thermocouple thermometer [13] and an 80PK-24 temperature probe. Measurements of PDI were obtained using the New Holmen Pellet Tester [23] where one hundred grams of pelleted samples were subjected to air flow within a perforated chamber for 30 seconds. Measurements of particle size were obtained using the WS Tyler Ro-Tap Sieve Shaker [24] where one hundred grams of complete feed were subjected to a dust-tight enclosed series of staked (No. 4, 6, etc.) American Society of Testing and Materials (ASTM) screens affixed to the Ro-Tap particle size analyzer and shaken for $10 \mathrm{~min}$.

Nutrient analysis consisted of moisture [25], crude protein [26], selected total amino acids [27], titanium dioxide [28], in vitro available lysine [29], and trypsin inhibitor complex activity [30]. In vitro available lysine and trypsin inhibitor complex activity were conducted by commercial laboratories $[31,32]$ in order to estimate the effects of thermal processing. The in vitro available lysine assay indicates lysine that is chemically intact and available to react with 1Fluro-2,4-dinitrobenzene following heat treatment [29]. The trypsin inhibitor activity assay 
indicates the ability of the various trypsin inhibitors to prevent trypsin hydrolysis of benzoyl-Larginine ethyl ester and is measured spectrophotometrically [30].

\section{Live Bird Performance}

A total of 900 Hubbard x Cobb 500 straight-run day old broiler chicks were obtained from a commercial hatchery [33]. Birds were housed in raised wired cages with nipple drinkers and trough feeders. Two identical rooms were utilized, containing 90 cages total. The temperature of the rooms was set at $32^{\circ} \mathrm{C}$ at $1 \mathrm{~d}$ of age and gradually reduced to $26^{\circ} \mathrm{C}$ for the final week of the study to optimize rearing conditions [34]. Each dietary treatment was provided to 10 replicate pens of 10 broilers. Feed and water were provided for ad libitum consumption. On d 15, 0.2\% $\mathrm{TiO}_{2}$ was added to each diet. Feed containing $0.2 \% \mathrm{TiO}_{2}$ was fed until the termination of the study on $\mathrm{d} 18$. On $\mathrm{d} 18$, birds were exposed to $4 \mathrm{~h}$ dark and then allowed to consume feed for $6 \mathrm{~h}$ to ensure that digesta was present in the ileum prior to excision for measuring digestible amino acid concentration [35]. Feed intake and bird weight were measured to calculate live weight gain per bird (LWG), mortality corrected feed conversion ratio (FCR), and digestible amino acid concentration (DAAC).

On $\mathrm{d} 18$ all birds were euthanized via cervical dislocation. Contents of the ileum, from the Meckel's diverticulum to approximately $5 \mathrm{~mm}$ proximal to the ileo-ceco-colonic junction, were flushed with distilled water into clean plastic containers. Digesta within a cage (or replicate) were pooled and stored at $-20^{\circ} \mathrm{C}$ until the samples were freeze-dried and sent to a commercial laboratory for amino acid and $\mathrm{TiO}_{2}$ analysis $[31,35]$. The digestible amino acid concentration (DAAC) was calculated for select amino acids.

Digestible Amino Acid Concentration was calculated using the formula: 
DAAC $(\%)=(\mathrm{AID} / 100) \times \mathrm{TAA}$

Where AID represents the apparent ileal digestibility value using the following formula; $\operatorname{AID}(\%)=\left[1-\left(\mathrm{TD}_{\mathrm{i}} / \mathrm{TD}_{\mathrm{O}}\right) \times\left(\mathrm{No}_{\mathrm{O}} / \mathrm{Ni}\right)\right] \times 100$.

Where $\mathrm{Td}_{\mathrm{i}}$ represents the concentration of $\mathrm{TiO}_{2}$ in the diet in grams per kilogram of $\mathrm{DM}$; $\mathrm{Td}_{\mathrm{o}}$ represents the concentration of $\mathrm{TiO}_{2}$ in the ileal digesta in grams per kilogram of DM output; Ni represents the concentration of nitrogen or AA in the diet in grams per kilogram DM; and No represents the concentration of nitrogen or AA in ileal digesta in grams per kilogram of DM [35]. The TAA value represents the total amino acid concentration found in the diet.

All animals were reared according to protocols established by the West Virginia University Animal Care and Use Committee [ACUC 15-0408].

\section{Statistical Analysis}

A 3 (diet formulation) $\times 3$ (thermal processing) factorial arrangement of treatments was used to explore main effects and interactions on broiler performance and DAAC. A randomized complete block design was utilized with one pen of 10 birds as the experimental unit. All data were analyzed using the GLM procedure of Statistical Analysis System [36]. Alpha was designated as 0.05 for significance, and letter superscripts were used to denote differences among treatment means using the F protected Fischer's LSD test when the main effect interactions were significant. 


\section{RESULTS AND DISCUSSION}

\section{Feed Manufacture}

Feed manufacture and pellet quality data were not replicated and should be considered descriptive (Table 2). Hot pellet temperature values decreased for Double Pelleted compared to Pelleted treatments, likely associated with increased lubrication from feed being conditioned twice. Pellet durability was increased for Double Pelleted compared to Pelleted treatments, likely associated with increased temperature, pressure, and moisture exposure that could gelatinize more starch and gel more proteins. The magnitude of improvement for the Basal + BBP was not as great compared to the Basal and Basal + MBM diets. Perhaps the starch associated with BBP combined with the lower soybean oil in the Basal + BBP formulation contributed to improved pellet binding. Pellet grinding with a roller mill was effective in standardizing diet particle size among treatments prior to feeding $(923-1047 \mu \mathrm{m})$. Standardized feed form allows for bird performance variations to be influenced by nutrient availability and not confounded by deviations in feed form. Diet storage in the dehumidified room prior to feeding was effective in standardizing diet moisture content $(9.9-10.8 \%)$.

\section{Live Performance}

Diet formulation and thermal processing effects on $18 \mathrm{~d}$ broiler performance variables are presented in Table 3. Broilers provided a Basal + MBM diet improved FCR $(\mathrm{P}=0.0046)$ compared to broilers fed Basal and Basal + BBP. This effect may have been associated with nutritional benefits of meat and bone meal. The inclusion of MBM in the diet could have improved the FCR due to increased non-essential amino acids in the diet. Previous research by Parsons et. al. demonstrated that various analyzed meat and bone meals contain different levels of non-essential amino acids [37]. It is thought that the presence of non-essential amino acids in 
the diet ensures the efficient use of the essential amino acids [37]. In the current study, the Basal + MBM exhibited increased non-essential amino acid levels, specifically the amino acid, glycine (Table 1). Past research by Corzo et al. identified that diets with the supplementation of the nonessential amino acid glycine to a low crude protein diet produced similar bird FCR compared to a control diet with adequate crude protein [38]. Wu et. al. have speculated that if an excess of nonessential amino acids are pronounced in the diet, the amino acids will undergo deamination and allow for cells to generate an abundance of energy that can be utilized for enhancing growth and performance [39].

Pelleting and Double Pelleting improved FCR compared to Unprocessed Mash ( $\mathrm{P}=0.0003)$. This effect may have been associated with thermal processes of pelleting decreasing antinutritional factors inherent in corn and soybean meal. Past research has identified that processing technologies that utilize heating under moist conditions may alter the physicochemical properties of non-starch polysaccharides [40]. A study performed by Saunders et al. evaluated the biological availability of wheat bran nutrients for unprocessed feed and pelleted feed by microscopically analyzing the aleurone layer of the cell walls, which encapsulates significant amounts of nutritive components within the cereal grain [41]. The microscopic analysis identified that as the feed underwent thermal processing a significant amount of cell wall breakage occurred to the aleurone layer when compared to unprocessed mash, ultimately improving opportunities for nutrient utilization. Furthermore, the improvement in FCR may be explained by thermal processing inactivating the trypsin inhibitor complex that may be prevalent in soybean meal. Analysis of trypsin inhibitor complex activity indicated that thermal processing decreased diet activity (Table 5). Past research by Erdaw et. al. demonstrated similar results when evaluating a complete feed ration utilizing the trypsin inhibitor complex assay [42]. The authors found that the trypsin 
inhibitor concentrations of thermally processed diets were reduced by $7.2 \%$ when compared to diets that were not thermally processed [42]. Clarke and Wiseman have indicated that modern commercial poultry should be fed soybean meals that analyze less than 4,000 TIU/g compared to formerly accepted levels of 6,000 to 8,000 TIU/g [43]. Furthermore, research by Hong et. al. demonstrated that diets containing trypsin inhibitor concentration exceeding 1,463 TIU/g can affect the performance of non-ruminant animals [44].

Formulation and processing effects interacted to affect LWG, digestible amino acid concentration of lysine, methionine, threonine, and cysteine $(\mathrm{P}<0.05)$. These effects likely were associated with nutritional benefits or detriments of thermal processes of pelleting being dependent on diet formulation. Improvements to LWG were apparent only when Basal + MBM diets were thermally processed $(\mathrm{P}<0.05)$. The previously mentioned main effect attributes such as increased non-essential amino acids, aleurone layer rupture, and decreased trypsin inhibitor complex may have supported this result $[13,38,45]$. The difference between benefits of thermal processing in the current study and detriments demonstrated in past research may be most associated with soybean meal source and trypsin inhibitor complex activity. In addition, the current study utilized high levels of mixer added fat that could decrease nutrient detriments due to mixer added fat having die-lubricating properties that may aid in maintaining amino acid availability due to allowing less friction to occur at the die.

The digestible amino acid concentration improved when Basal and Basal + MBM diets were thermally processed. However, digestible lysine and cysteine concentrations decreased when Basal + BBP were thermally processed (Table 4). The differences in digestibility were likely associated with variations in reducing sugars among formulations. Past research has speculated that using an alternative feed ingredient that consists of starch and non-reducing sugars; such as 
bakery by-product, may result in deleterious effects on lysine availability as the feed endures thermal processing. The starch and non-reducing sugars found in bakery by-product may be hydrolyzed during processing and extrusion, whereby resultant reducing sugars react with lysine [46]. Amadori product are formed that bind lysine to reducing sugars resulting in decreased lysine availability to the animal [47].

\section{Descriptive Feed Analysis}

Descriptive feed analyses of total lysine, in vitro available lysine, trypsin inhibitor complex activity, and mean values for digestible lysine concentration are provided for comparison in Table 5. The total lysine and in vitro available lysine analyses indicated that the treatments had numerically similar contents regardless of diet formulation or degree of thermal processing. However, digestible lysine concentration significantly decreased when Basal + BBP diets were thermally processed. These values followed numeric trends for Basal + BBP trypsin inhibitor complex activity for unprocessed and processed diets. The data indicate that the in vitro available lysine and digestible lysine concentration did not correspond. Moughan et al. stated that for many protein sources, not all in vitro available lysine is digested and absorbed from the small intestine of the animal and therefore the available lysine assays are not always a reliable method of determining the lysine digestibility of the feed [48]. 


\section{CONCLUSION AND APPLICATIONS}

1. Broilers provided Basal + MBM diet improved FCR $(P=0.0046)$ compared to broilers fed Basal and Basal + BBP. This effect may have been associated with nutritional benefits of the particular meat and bone meal.

2. Pelleting and Double Pelleting improved FCR compare to Unprocessed Mash $(\mathrm{P}=0.0003)$. This effect may have been associated with thermal processes of pelleting decreasing anti-nutritional factors inherent in the particular corn and soybean meal.

3. Formulation and processing effects interacted to affect $L W G$, digestible amino acid concentration of lysine, methionine, threonine, and cysteine $(P<0.05)$. These effects may have been associated with nutritional benefits or detriments of thermal processes of pelleting being dependent on diet formulation. 


\section{REFERENCES AND NOTES}

1. "Poultry and Nutrition and Feed." Poultry and Nutrition and Feed ::: FAO's Animal Production and Health Division. Food and Agriculture Organization of the United Nations, 7 Mar. 2014. Web. 29 June 2017.

2. C. K. Gehring, K. G. S. Lilly, L. K. Shires, K. R. Beaman, S. A. Loop, J. S. Moritz. 2011. Increasing mixer-added fat reduces the electrical energy required for pelleting and improves exogenous enzyme efficacy for broilers. J Appl. Poult. Res. 20 (1): 75-89.

3. Behnke, K. C. 1996. Feed manufacturing technology: Current issues and challenges. Anim. Feed Sci. Technol. 62:49--57.

4. Jensen, L. S., L. H. Merrill, C. V. Reddy, and J. Mc-Ginnis. 1962. Observations on eating patterns and rate of food passage of birds fed pelleted and unpelleted diets. Poult. Sci. 41:1414-1419.

5. Hott, J. M., N. P. Buchanan, S. E. Cutlip, and J. S. Moritz. 2008. The effect of moisture addition with a mold inhibitor on pellet quality, feed manufacture, and broiler performance. J. Appl. Poult. Res. 17:262-271.

6. Moritz, J. S., R. S. Beyer, K. J. Wilson, K. R. Cramer, L. J. McKinney, and F. J. Fairchild. 2001. Effect of moisture addition at the mixer to a corn-soybean based diet on broiler performance. J. Appl. Poult. Res. 10:347-353.

7. Nir, I., Y. Twina, E. Grossman, and Z. Nitsan. 1994. Quantitative effects of pelleting on performance, gastrointestinal tract and behavior of meat-type chickens. Br. Poult. Sci. 35:589-602. 
8. Behnke, K. C. 1994. Factors affecting pellet quality. Pages 44-54 in Proc. Maryland Nutr. Conf., College Park, MD. Maryland Feed Ind. Counc. and Univ. Maryland, College Park.

9. Scheideler, S. E. 1991. Pelleting is important for broilers. Pages 1-7 in Proc. 18th Annu. Carolina Poult. Nutr. Conf., Charlotte, NC. North Carolina State Univ., Raleigh.

10. Silversides, F. G. and Bedfor, M. R. 1999. Effect of pelleting temperature on the recovery and efficacy of xylanase enzyme in wheat-based diets. Poult. Sci. 78: 1184-1190.

11. Plavnik, I. , E. Wax, D. Sklan, and S. Hurwitz. 1997. The response of broiler chickens and turkey poults to steam-pelleted diets supplemented with fat or carbohydrates. Poult. Sci. 76:1006-1013.

12. R. E. Loar, II, K. G. S. Wamsley, A. Evans, J. S. Moritz, A. Corzo. 2014. Effects of varying conditioning temperature and mixer-added fat on feed manufacturing efficiency, 28- to 42day broiler performance, early skeletal effect, and true amino acid digestibility. J Appl. Poult. Res. 23: 3, pp 444-455.

13. A. E. Lamp, A. M. Evans, J. S. Moritz. 2015. The effects of pelleting and glucanase supplementation in hulled barley based diets on feed manufacture, broiler performance, and digesta viscosity. J Appl. Poult. Res. 24: 3, pp 295-303.

14. Østergård K. Björck I. Vainionpää J. 1989. Effects of extrusion cooking on starch and dietary fiber in barley Food Chem. 34:215- 227.

15. Thomas, M., D. J. van Zuilichem, and A. F. B. Van der Poel. 1997. Physical quality of pelleted animal feed. 2. Contribution of processes and its conditions. Anim. Feed Sci. Tech. 64:173-192. 
16. Pickford, J.R. 1992. Effects of processing on the stability of heat labile nutrients in animal feeds. Pages 177 - 192 in: Recent Advances in Animal Nutrition. P. C. Garnsworthy, W. Haresign, D.J.A. Cole, ed. Butterworth-Heinemann, Oxford, U.K.

17. Hendricks, W.H., P.J. Maughan, H. Boer, and A.F.B. van der Poel. 1994. Effects of extrusion on the dye-binding, fluorodinitrobenzene-reactive and total lysine content of soyabean meal and peas. Ani. Feed Sci. and Tech. 48: $99-109$.

18. Agri Stats Inc., Fort Wayne, IN, 46825.

19. Digestible amino acids were based on $90 \%$ of the digestible lysine value suggested by $\mathrm{P}$. B. Tillman and W.A. Dozier. 2013. Current Amino Acid Considerations for Broilers: Requirements, Ratios, Economics. www.thepoultryfederation.com for $8-14$ day broilers. Therefore digestible lysine was set at $1.08 \%$.

20. Republic Mills, Inc. Okolona, OH 43545.

21. Bakery Feeds in Butler, KY 41006.

22. California Pellet Mill Master Model HD Series 1000. CPM Co., Crawfordsville, IN

23. Pellet quality was assessed one day following production using the New Holmen NHP Portable Pellet Durability Tester, Lignotech USA, INC., Rithschild, WI. $100 \mathrm{~g}$ of pellets were placed in the chamber, blown about for 60 seconds by a jet of air, and then weighed, giving a direct read of pellet durability. Fines are removed during the blowing process.

24. WS Tyler Ro-Tap Sieve Shaker One hundred grams of product for each treatment was placed in a dust-tight enclosed series of staked (No. 4, 6, etc.) American Society of Testing and Materials (ASTM) screens affixed to the Ro-Tap particle size analyzer and shaken for $10 \mathrm{~min}$. The screens were then separated and weighed. Particle size was calculated by subtracting the weight of the screen from the final weight of screen and 
sample after shaking. The mean geometric particle size and log normal geometric SD were calculated as described by McEllhiney (McEllhiney, R. R. 1994. Determining and expressing particle size. Pages 545-547 in Feed Manufacture Technology IV. Am. Feed Ind. Assoc. Inc., Arlington, VA.)

25. AOAC Authors. Official methods of analysis Proximate Analysis and Calculations Moisture (M) Animal Feed - item 106. Association of Analytical Communities, Gaithersburg, MD, 17th edition, 2006. Reference data: Method 934.01 (4.1.03); NFNAP; WATER.

26. AOAC Authors. Official methods of analysis Proximate Analysis and Calculations Total Nitrogen or Crude Protein (CP) - item 76. Association of Analytical Communities, Gaithersburg, MD, 17th edition, 2006. Reference data: Method 990.03; NITR; NT. 27. AOAC Authors. Official methods of analysis Amino Acids Analysis Complete Amino Acid Profile (AAP) - item 72. Association of Analytical Communities, Gaithersburg, MD, 17th edition, 2006. Reference data: Method 982.30 E(a,b,c); NFNAP; NITR; AA.

28. Sigma-Aldrich. St. Louis, MO.

29. AOAC Authors. Official methods of analysis Amino Acids Analysis Available Lysine (AL) - item 68. 1-Fluro-2,4-dinitrobenzene (DNFB) reacts with free terminal amino groups in proteins, forming DNFB-terminal-Amino lysine which is stable to acid hydrolysis. Test portion is acid hydrolyzed and unavailable lysine is determined with amino acid analyzer; total lysine is determined on untreated test portion. Available lysine, which was bound by DNFB, is determined by difference. Association of Analytical Communities, Gaithersburg, MD, 17th edition, 2006. Reference data: Method 975.44; NFNAP; NITR; LYSAVL. 
30. AOCS Official Method Ba 12-75. Reapproved 2017. Trypsin Inhibitor Activity.

DEFINITION The ability of the various trypsin inhibitors to prevent trypsin hydrolysis of benzoyl-L-arginine ethyl ester is measured spectrophotometrically. No unit of activity is currently assigned. The activity of the inhibitors is expressed as the amount of twice crystallized trypsin (TRL) inhibited by one milligram of inhibitor. SCOPE Applicable to soybean meals and flours (raw and toasted), to soy protein concentrates and isolates, and to corn-soy mixtures.

31. Experiment Station Chemical Laboratories, Agricultural Experiment Station, Univ. Missouri, Columbia.

32. New Jersey Feed Laboratory. Ewing Township, NJ.

33. Pilgrims Pride Hatchery. Moorefield, WV.

34. Cobb-Vantress, Inc.

35. S. A. Adedokun, P. Jaynes, R. L. Payne, and T. J. Applegate. 2015. Standardized Ileal Amino Acid Digestibility of Corn, Corn Distiller's Dried Grains with Solubles, Wheat Middlings, and Bakery By-Product in Broilers and Laying Hens. Poult. Sci. 94:24802487.

36. SAS Institute. 2000. The SAS System for Windows 2000. Release 8.1. SAS Inst. Inc., Cary, NC.

37. Parsons, C. M., F. Castanon, and Y. Han. 1997. Protein and amino acid quality of meat and bone meal. Poult. Sci. 76:361-368

38. A. Corzo, C.A. Fritts, M.T. Kidd, B.J. Kerr. 2005. Response of broiler chicks to essential and non-essential amino acid supplementation of low crude protein diets, In Animal Feed Science and Technology. 118: 3-4, pp 319-327. 
39. Wu, Guoyoa, Zhenlong Wu, Zhaolai Dai, Ying Yang, Weiwei Wang, Chuang Liu, Bin Wang, Junjun Wang, and Yulong Yin. "Dietary Requirements of "nutritionally nonessential Amino Acids" by Animals and Humans." Springer 44 (2012): 1107-113.

40. Bedford, M. R. 2002. The role of carbohydrases in feedstuff digestion, in: McNab, J. M. and Boorman, K. N. (Eds.), Poultry Feedstuffs: Supply, Composition and Nutritive Value, Wallingford, CAB International, pp: 319-336.

41. Saunders, R. M., Walker, H. G. and Kohler, G. O. 1969. Aleurone cells and the digestibility of wheat mill feeds. Poult. Sci. 48: 1497-1503.

42. M. M. Erdaw, M. M. Bhuiyan, P. A. Iji. 2017. Response of broiler chicks to non-steamor steam-pelleted diets containing raw, full-fat soybean meal. J Appl. Poult. Res. 26:2, pp 260-272.

43. Clark, E., and J. Wiseman. 2001. Comparison of nutritional value of full fat soyabean meals for broiler chicks in the UE. Br. Poult. Sci. 41:688-689.

44. Hong K. J., Lee C. H., Kim S. W.. 2004. Aspergillus oryzae GB-107 fermentation improves nutritional quality of food soybeans and feed soybean meals. J. Medicinal Food. 7:430-435.

45. Østergård K. Björck I. Vainionpää J. Effects of extrusion cooking on starch and dietary fiber in barley Food Chem. 198934215227

46. Dale, N. 1992. Pelleting Effects on Lysine Bioavailability in Diets Containing Dried Bakery Product. J. Appl. Poultry Res. 1:84-87.

47. Dills, W. L. Jr, 1993. Protein fructoslyation: fructose and the Maillard reaction. Am. J. Clin. Nutr. 58(suppl):779S-783.S. 
48. Moughan, P.J. and Rutherfurd, S. M. 1996. A new method for determining digestible reactive lysine in foods. Journal of Agriculture, Food and Chemistry. 44, 2202-2209. 


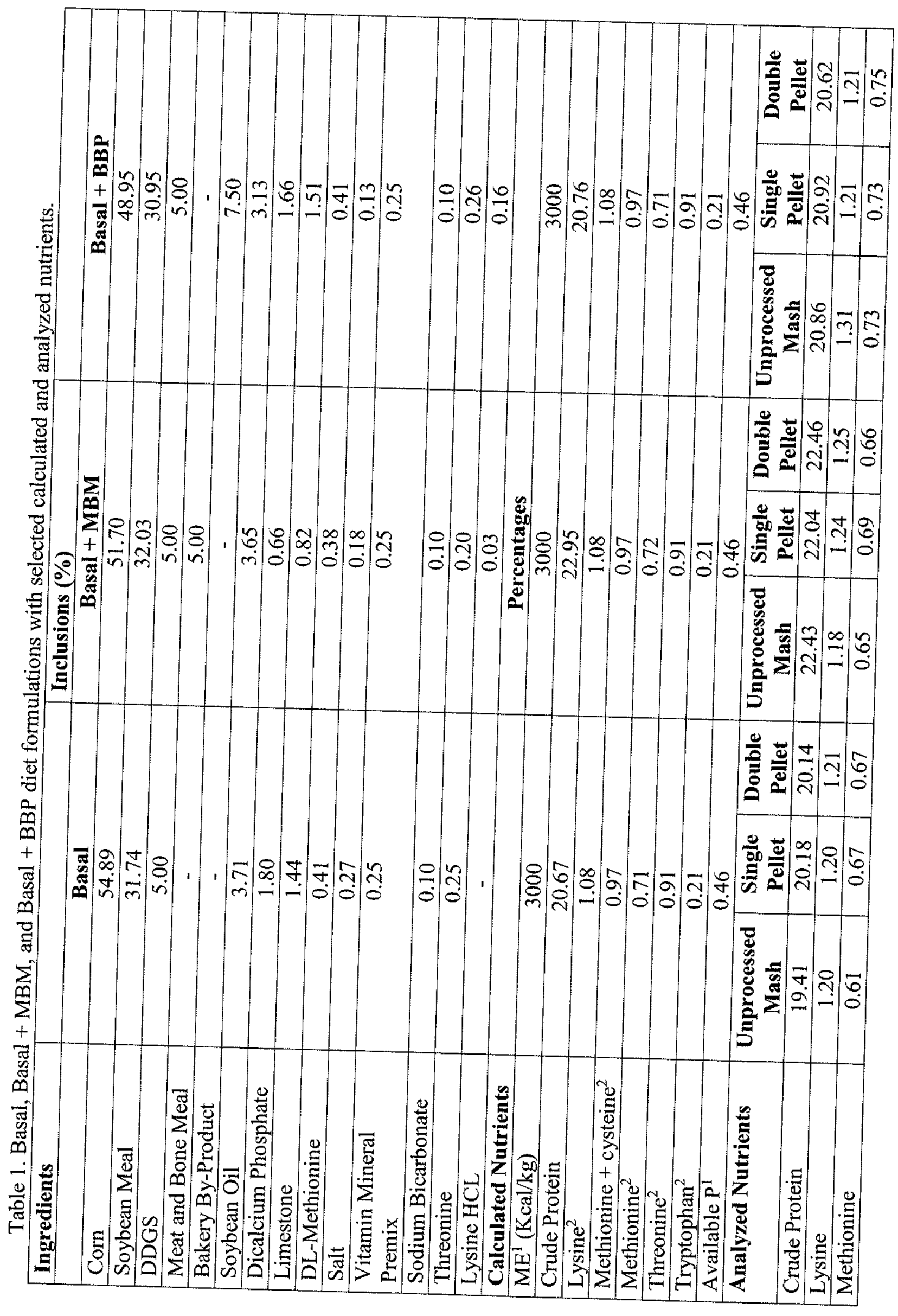




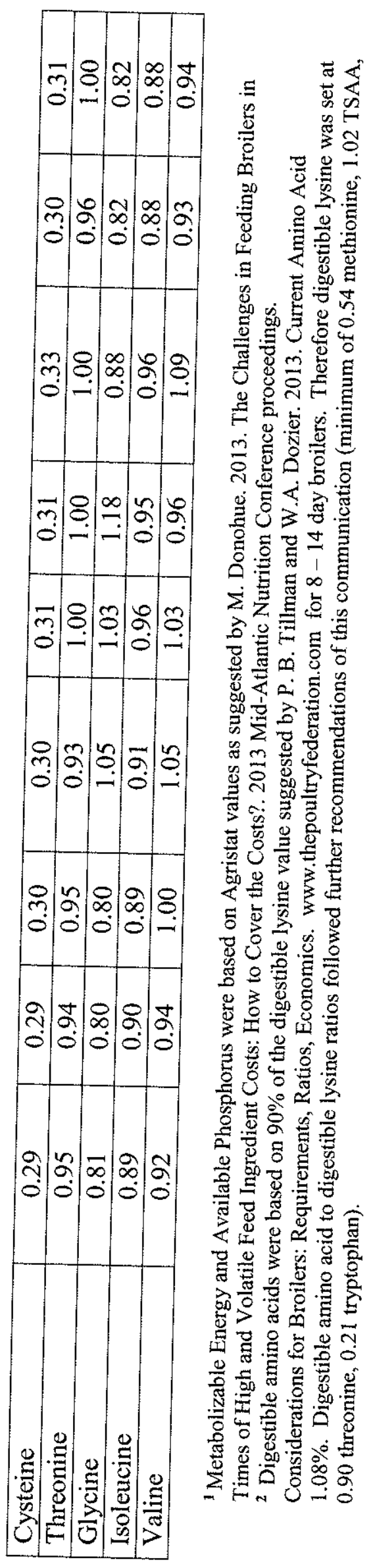

m 


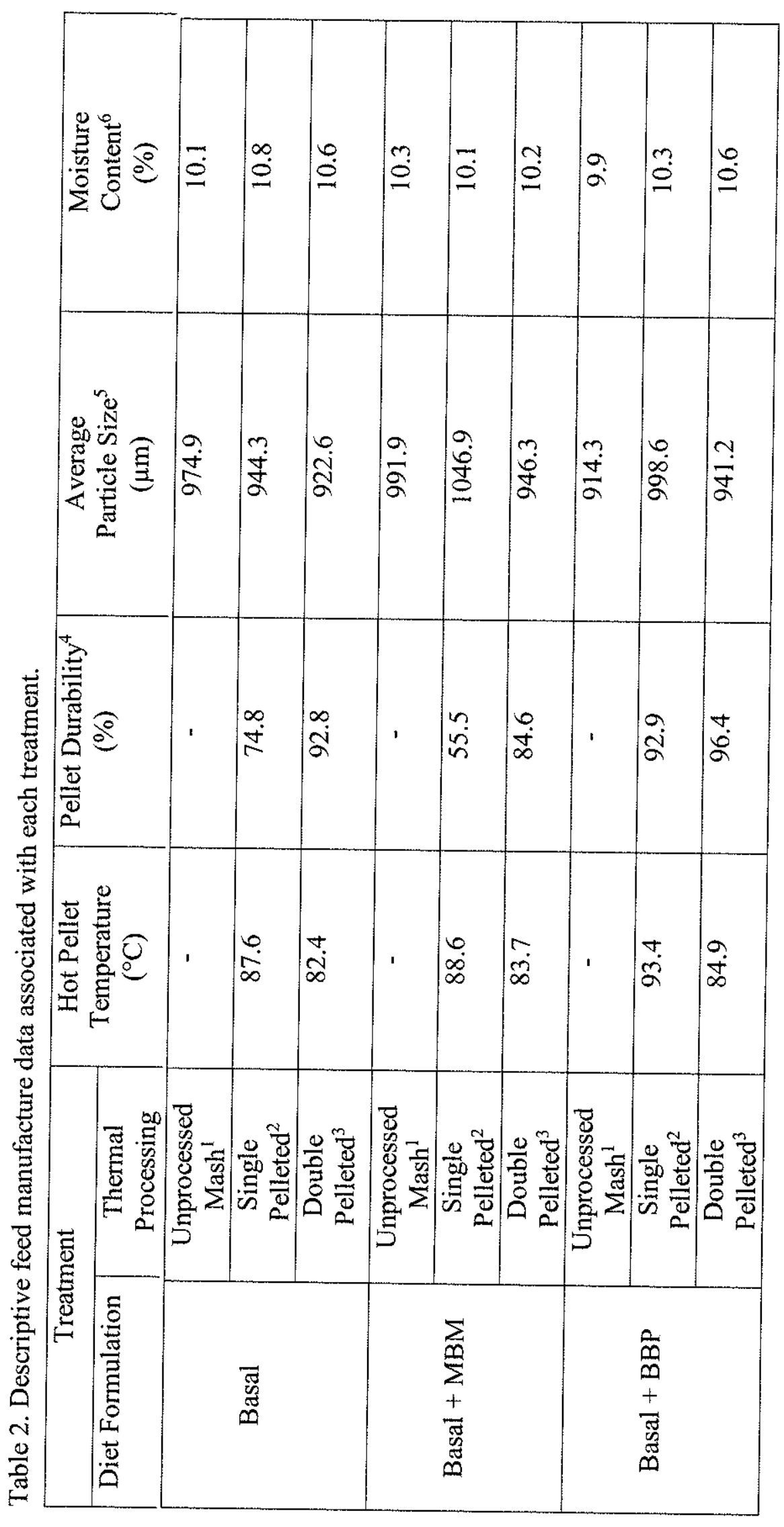

\& 


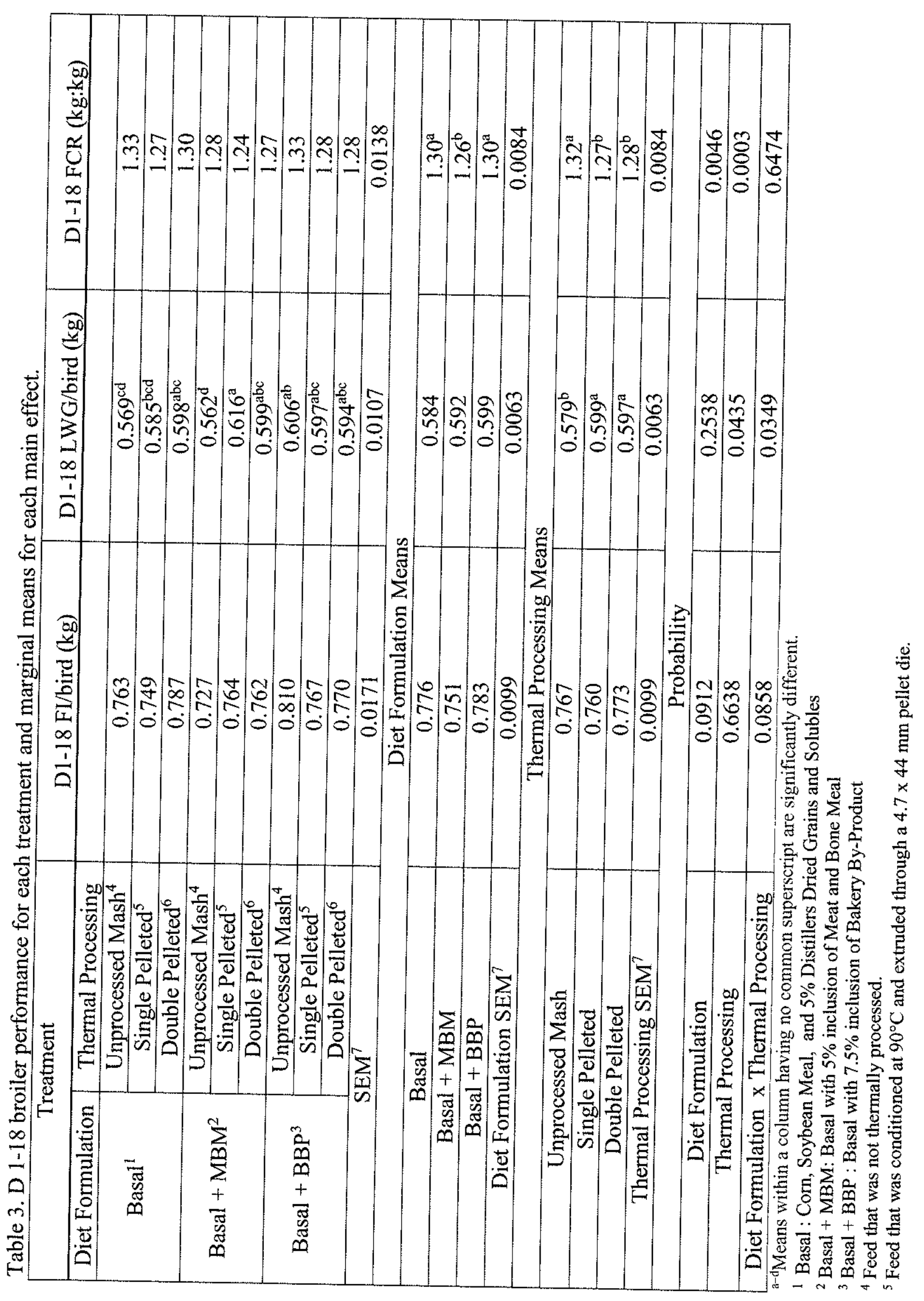




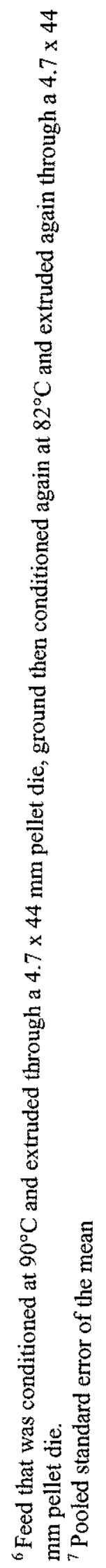




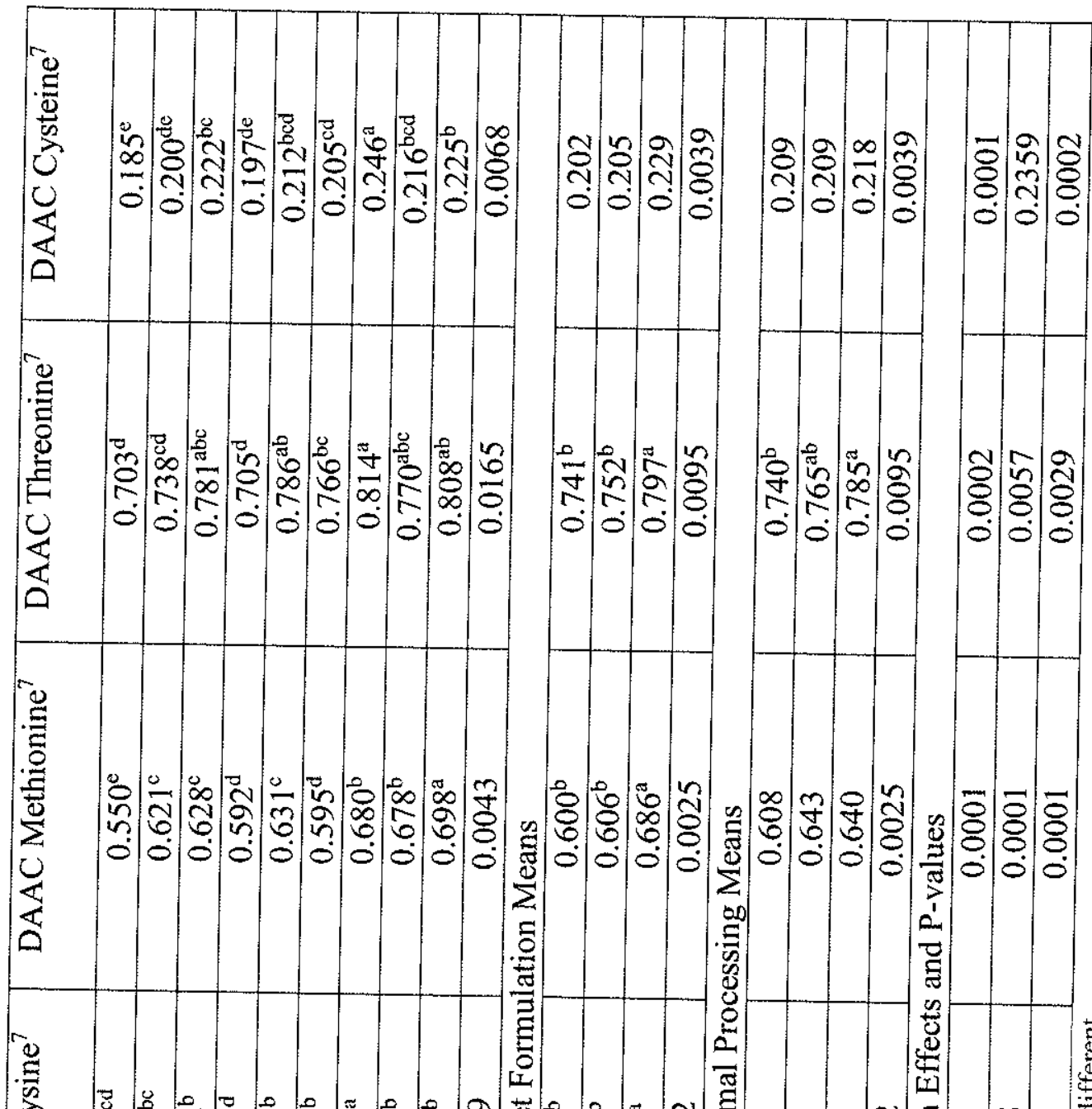

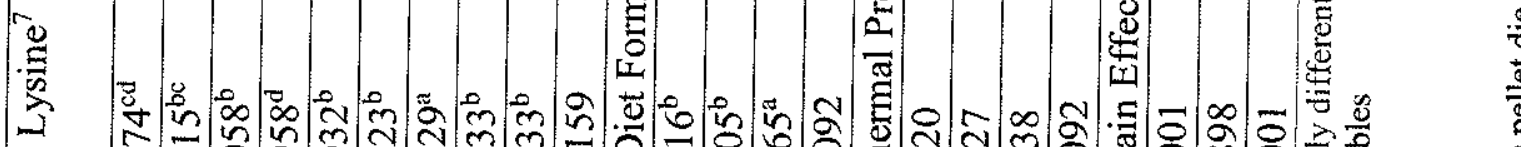
䓕
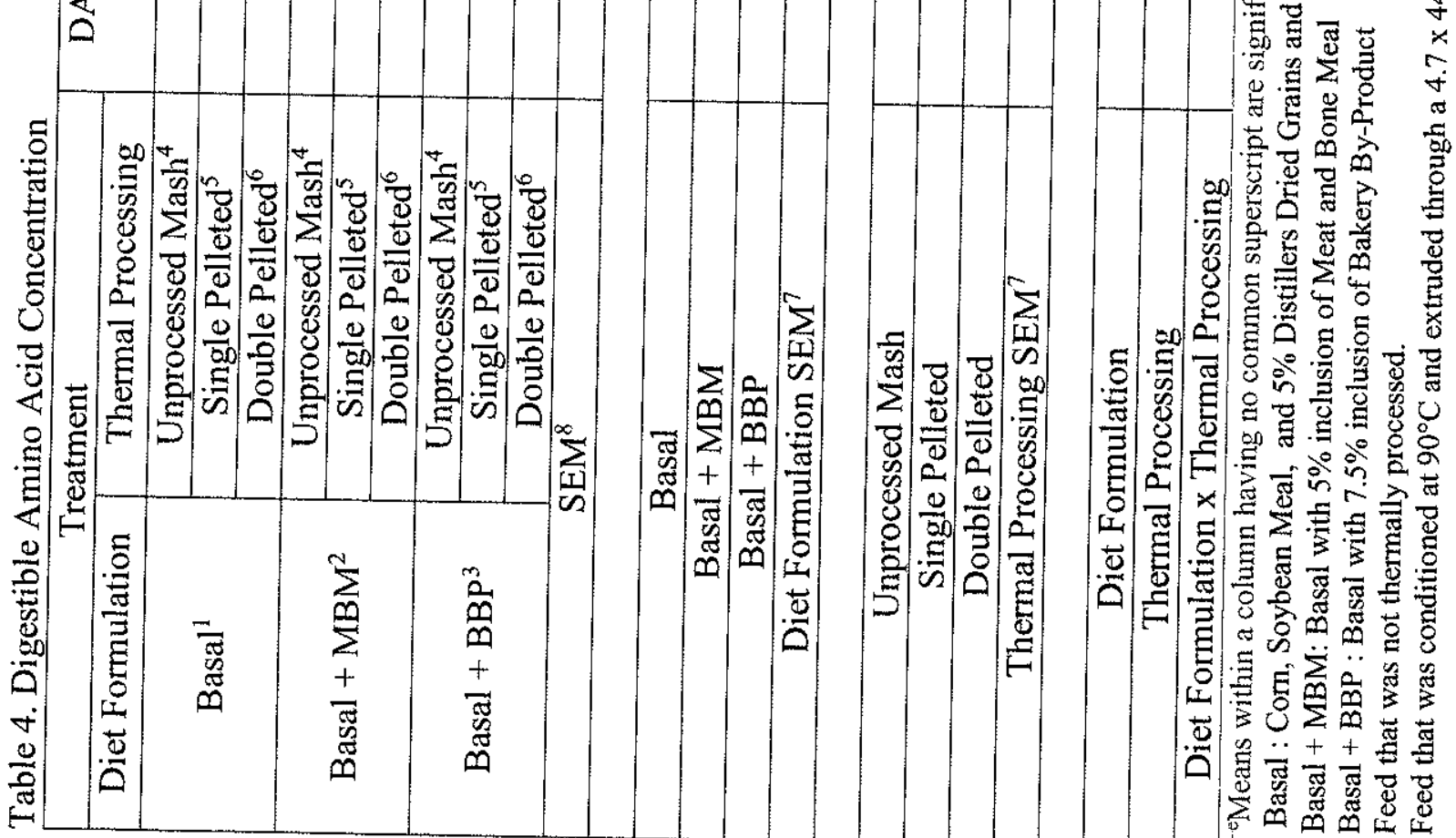


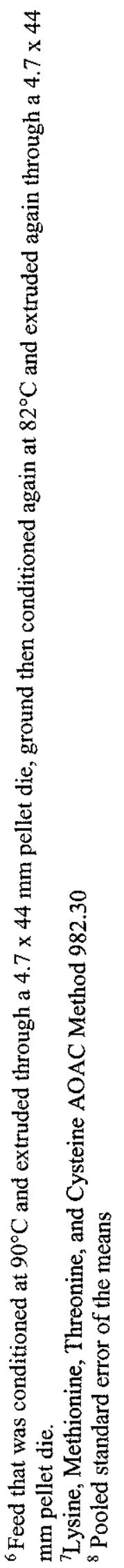




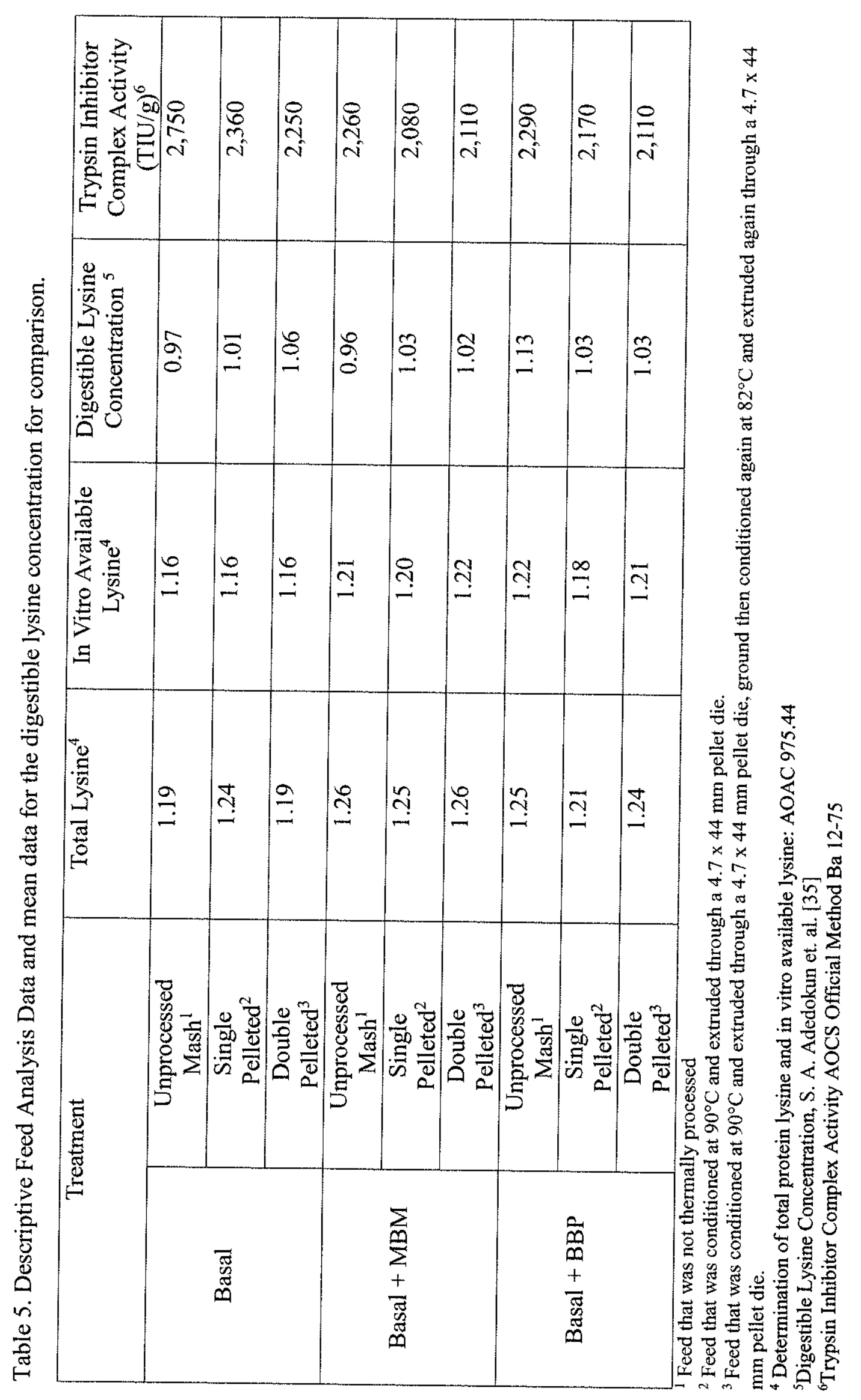




\title{
CHAPTER 3: The Effects of Various Rock Phosphate Feed Ingredients on Feed Manufacture Variables and Pellet Quality
}

\author{
A. N. Bergeron and J. S. Moritz \\ Division of Animal and Nutritional Sciences, West Virginia University, Morgantown, West \\ Virginia, 26506
}

Phone: 304-293-1911

Fax: 304-293-2232 
SUMMARY: Diets with high levels of corn distillers dried grains and solubles (DDGS) are notoriously difficult to pellet due to their high fat and fiber content. Therefore the addition of inorganic phosphate feed ingredients, especially tricalcium phosphate has been anecdotally thought to improve feed manufacture and pellet quality of diets high in corn DDGS. The objective of the current study was to evaluate the effects of various inorganic phosphate feed ingredients on feed manufacture and feed quality. Feed was manufactured on three separate days, each day denoting a replication of the experiment. Six experimental diets consisted of corn- and soybean meal-based diets without meat and bone meal were formulated to include either: 1) FP\&S Dicalcium Phosphorus (DCaP), 2) Nexfos, 3) Bolifor, 4) Deflourinated Phosphorus, 5) Mixture (1/5 Bolifor, 1/5 MSP, 3/5 DCP), or 6) Bolifor + SiO2. The inclusion of Deflourinated Phosphorous demonstrated decreased hot pellet temperature, motor amperage and pellet quality while increasing production rate relative to the diet that included Bolifor $+\mathrm{SiO} 2(\mathrm{P}<0.05)$. It is thought that the improvements demonstrated for this product could be due to the physical aspects of the product. The inorganic feed phosphate ingredient that exhibited the densest and smallest particle size was Deflourinated Phosphorous. The small-diameter and high-density particles of Deflourinated Phosphorous could of provided greater inertia within the die, thus enhancing die scouring. The use of Bolifor demonstrated a significantly increased hot pellet temperature, but maintained similar motor amperage and production rate relative to diets that included DCP or Nexfos. The majority of pellet quality variables showed that diets containing Bolifor or DCP were similar yet superior to the diet containing the inorganic feed phosphate ingredient Nexfos.

Keywords: feed manufacture, inorganic feed phosphate, pellet quality 


\section{DESCRIPTION OF PROBLEM}

Feed accounts for 60 to $75 \%$ of total production cost in poultry production [1]. Therefore it is important for poultry nutritionist to focus on a method of providing the most cost efficient, yet performance promoting diet for the chicken. With the cost of conventional feed ingredients constantly rising, the utilization of alternative feed ingredients may be beneficial to a least-cost efficient diet formulation. A current alternative feed source that is highly utilized in the poultry industry is corn distiller dried grains with solubles (DDGS). This feed ingredient is a by-product of dry-milled ethanol production [2]. DDGS is a nutrient rich feed ingredient that is well documented for supplementing adequate energy and protein to the chicken, yet pellet throughput and pellet quality concerns are notorious when high fat DDGS are utilized in the diet [3].

The addition of inorganic phosphorous sources to the feed may improve the quality of the pellet. The addition of inorganic phosphorus feed sources can also improve the availability of phosphorus in the diet. Commercial poultry diets are deficient in nonphytate phosphorus, therefore the supplementation of inorganic feed phosphate allows for the requirements to be met. However, inorganic feed phosphate sources are highly variable in regards to source, manufacture techniques, nutrient content, particle size, and density of the ingredient [4]. Accompanied with variations of the feed ingredient, information regarding the effects of inorganic feed phosphates on pelleting parameters are not well known.

Inorganic feed phosphates have abrasive properties that may scour the pellet die and affect feed production rate, energy use of the pellet mill, or a combination of the factors [5]. Inorganic feed phosphate particles have been proposed to maintain a clean die due to the ability to dislodge residual feed that may adhere to the inner die surface [5-7]. Therefore, it is prudent to 
have an understanding of various inorganic feed phosphate sources and their effects on feed manufacturing.

The objective of the current study is to evaluate the effects of various inorganic phosphate feed ingredients on feed manufacture and pellet quality. Each area evaluated had varying factors. Feed manufacture variables consisted of hot pellet temperature (HPT), motor amperage, production rate, conditioner electrical energy (CEE), and pellet mill electrical energy (PMEE). Pellet durability variables consisted of New Homen Pellet Tester (NHPT), pellet durability index (PDI), modified pellet durability index (MPDI), and percent pellets.

\section{MATERIALS AND METHODS}

\section{Diet Preparation}

Six commercially available inorganic feed phosphate sources were used in this experiment. 1) FP\&S Dicalcium Phosphorus (DCaP), 2) Nexfos, 3) Bolifor, 4) Deflourinated Phosphorous, 5) Mixture (1/5 Bolifor, 1/5 MSP, 3/5 DCP), and 6) Bolifor $+\mathrm{SiO}_{2}$. The respective ingredients bulk density and particle size are listed in Table 1. The DCaP, Nexfos, and Bolifor were created by reacting calcium carbonate and deflourinated phosphoric acid [8]. The Deflourinated Phosphorous was created by hydro-thermo-acid reprocessing of apatite concentrate which reduces the fluorine in the product [9]. Diets were formulated in accordance with the Cobb 500 broiler recommendation for the starter phase. Diets were formulated with the use of high fat DDGS. Diets were also formulated without the use of meat and bone meal to ensure that the level of inorganic feed phosphorus source would be maximized [10] (Table 2).

Six $454 \mathrm{~kg}$ batches were created with the 6 inorganic phosphate feed sources, the $454 \mathrm{~kg}$ batches represented an experimental unit which underwent further processing that was replicated by day of manufacture. 


\section{Feed Manufacture}

All diets were batched and manufactured at the West Virginia University pilot feed mill. Mash diets were conditioned using a short-term conditioner $(0.31 \times 1.30 \mathrm{~m}, 10$-s retention time)[11] with a constant temperature of $82.2^{\circ} \mathrm{C}$. Pellets extruded through a 4.7 (diameter) $\mathrm{x}$ $44 \mathrm{~mm}$ (effective thickness) pellet die without relief using a 40HP California Pellet Mill [11]. The rate of the feed entering the conditioner was kept constant to ensure that differing rates would not cofound manufacturing variables. Post pelleting, each diet was cooled on a horizontal belt cooler [12] using forced ambient air. Feed manufacturing was replicated three times utilizing the six inorganic feed phosphate treatments in a randomized complete block design.

Prior to collecting feed manufacture data, $454 \mathrm{~kg}$ of non-treatment feed was utilized to warm the pellet die in order to reach the optimum temperature of $82.2^{\circ} \mathrm{C}$. Through this technique a standardized time of 3 minutes was determined the necessary time to raise the mash temperature to the optimal level.

\section{Feed Analysis}

In order to assess the feed manufacture and pellet quality effects, several variables were measured. The variables measured for feed manufacture include: hot pellet temperature [15], motor amperage, production rate, conditioner electrical energy usage (CEE), pellet mill electrical energy usage (PMEE). Hot pellet samples were placed on a mesh screen and immediately cooled using ambient air and a fan for 12 minutes [16], samples were then pooled by placing feed into a general sample bag specific to treatment of inorganic feed phosphate ingredient. Feed samples were then sent to a commercial laboratory for further analysis of total phosphorus and calcium content of the feed [17]. 
Pellet durability was evaluated based on New Holmen Pellet Test (NHPT) [18], pellet durability index (PDI) [19], modified pellet durability index (MPDI) [19], and pellet percentage [20] noted in Table 3. Individual inorganic feed phosphate sources were analyzed on characteristics of particle size [13] and bulk density [14](Table 1).

\section{Inorganic Feed Phosphate Images}

A model AIR AO1 Imager [21] was used to capture 5x magnification images of the Dicalcium Phosphorus, Nexfos, Bolifor, Deflourinated Phosphorous, and Mixture (1/5 Bolifor, $1 / 5 \mathrm{MSP}, 3 / 5 \mathrm{DCP}$ ) (Figure 1). The images are to demonstrate the variations in the angularity of the inorganic feed phosphates.

\section{Statistical Analysis}

A randomized complete block design was utilized with day of feed manufacture as the experimental unit. All data were analyzed using the GLM procedure of Statistical Analysis System [36]. Alpha was designated as 0.05 for significance, and letter superscripts were used to denote differences among treatment means using the F protected Fischer's LSD test when the main effect interactions were significant.

\section{RESULTS AND DISCUSSION}

\section{Inorganic Feed Phosphate}

Inorganic Feed Phosphate data were not replicated and should be considered as descriptive data (Table 1). The greatest magnitude in difference for descriptive inorganic feed phosphorous data variable was observed when comparing Deflourinated Phosphorous to the remaining products. The diet that included the Deflourinated Phosphorous had decreased particle size and increased bulk density when compared to other inorganic feed phosphate within the study. The products consisting of DCP, Bolifor, and Nexfos were similar in particle size and 
bulk density. The Mixture (1/5 Bolifor, 1/5 MSP, 3/5 DCP) product had decreased particle size yet similar bulk density to the $\mathrm{DCP}$, Bolifor, and Nexfos products. The Bolifor $+\mathrm{SiO} 2$ product had decreased particle size and density. The densest and smallest particle size inorganic feed phosphate used in this study was Deflourinated Phosphorous, it is thought that small-diameter and high-density particles provided greater inertia within the die, thus enhancing die scouring as found in recent literature by Wamsley et al. regarding inorganic feed phosphate [23].

\section{Physical Attributes of Inorganic Feed Phosphate Ingredients}

A model AIR AO1 Imager was used to capture $5 \mathrm{x}$ magnification images of the Dicalcium Phosphorus, Nexfos, Bolifor, Deflourinated Phosphorous, and Mixture (1/5 Bolifor, 1/5 MSP, $3 / 5 \mathrm{DCP}$ ), these images identified the physical characteristics of the inorganic phosphorus sources (Figure 1). The physical properties of inorganic feed phosphate can also improve production methodologies, as seen above the Deflourinated Phosphorous identifies as a small particle, yet has several jagged edges, which differ from the Dicalcium Phosphorus, Nexfos, Bolifor, and Mixture (1/5 Bolifor, 1/5 MSP, 3/5 DCP) products. The angularity of Deflourinated Phosphorous relative to the Dicalcium Phosphorus, Nexfos, Bolifor, and Mixture (1/5 Bolifor, 1/5 MSP, $3 / 5 \mathrm{DCP}$ ) products may improve feed production methodologies due to the abrasive nature of the Deflourinated Phosphorous product. Wamsley et. al. identified that structure angularity could coincide with production methodologies by cleaning the die due to dislodging residual feed that would adhere to the inner die surface, enhancing throughput, electrical energy usage or both [23].

\section{Feed Manufacture and Pellet Quality}

Feed manufacturing and pellet quality variables are presented in Table 3. Inorganic feed phosphate sources had an effect on frictional force within the pellet die that influenced hot pellet 
temperature, motor amperage, production rate, and pellet quality (Table 3). The greatest magnitude in difference for feed manufacture and pellet quality variables was observed when comparing diets containing Deflourinated Phosphorous and diets containing Bolifor $+\mathrm{Si02}$. The diet that included the Deflourinated Phosphorous demonstrated decreased hot pellet temperature, motor amperage and pellet quality while demonstrating increasing production rate relative to the diet that included Bolifor $+\mathrm{SiO} 2(\mathrm{P}<0.05)$. Decreased hot pellet temperature could lead to an increased amino acid availability. Research by Papadopoulos indicated that high processing temperatures are notoriously known to degrade amino acids, ultimately rendering the amino acid unavailable to the bird and hindering broiler performance [24]. The diet that included Bolifor demonstrated significantly increased hot pellet temperature but maintained similar motor amperage and production rate relative to diets that included DCP or Nexfos. The majority of pellet quality variables showed that diets containing Bolifor or DCP were similar, but superior to the diet containing Nexfos $(p<0.05)$. Cutlip et. al. evaluated the effects of pellet quality on broiler performance, this studied concluded that small improvements in pellet quality (i.e., 4.0 percentage point improvement in the pellet durability index) may significantly improve broiler performance (i.e., 20 point decrease in feed conversion ratio) while maintaining similar broiler weight gain [25]. Additional research by Moritz and colleagues [26] demonstrated that feeding broilers diets differing by 4.0 percentage points in PDI (67.42 vs. 71.75) decreased feed conversion ratio by 2 points and maintained live weight gain. The current study exhibited a 3 percentage improvement of PDI (89.03 vs. 91.78) for the treatment diets DCP and Bolifor relative to the other diets, this improvement of pellet durability could lead to beneficial effects for broiler performance. The addition of MSP and DCP to Bolifor in diets demonstrated a 
decreased hot pellet temperature relative to the diet that included Bolifor per se; however, additional feed manufacture and the majority of pellet quality variables were not improved. 


\section{CONCLUSION AND APPLICATIONS}

1. The use of Deflourinated Phosphorous at high inclusion levels in corn and soybean meal based diets demonstrated decreased hot pellet temperature, motor amperage, and pellet quality relative to the other inorganic feed phosphate ingredients. It is speculated that the physical aspects of the Deflourinated Phosphorous ingredient allowed for a die scouring effect.

2. The use of Bolifor demonstrated a significantly increased hot pellet temperature, but maintained similar motor amperage and production rate relative to diets that included DCP or Nexfos.

3. The majority of pellet quality variables showed that diets containing Bolifor or DCP were similar yet superior to the diet containing the inorganic feed phosphate ingredient Nexfos. 


\section{REFERENCE AND NOTES}

1. Jurgens, et al. "Poultry Nutrition and Feeding." Animal Nutrition Handbook, 2014, pp. $410-424$.

2. "DDGS." U.S. Grains Council, 25 Apr. 2017, www.grains.org/buyingselling/ddgS

3. Behnke K. C. 2007. Feed Manufacturing Consideration for Using DDGS in Poultry and Livestock Diets. Proceedings of the $5^{\text {th }}$ Mid-Atlantic Nutrition Conference. Pp 77-81

4. Lima F. R. Mendonca C. X. Jr. Alvarez J. C. Ratti G. Lenharo S. L. R. Kahn H. Garzillo J. M. F. 1995. Chemical and physical evaluations of commercial dicalcium phosphates as sources of biologically available phosphorus for broiler chicks. Poult. Sci. 74:16591670.

5. Behnke K. C. 1981. Pellet mill performance as affected by mineral source. Feedstuffs 53:34-36.

6. Verner W. A. 1988. Phosphates in pelleting: Best cost vs. least cost. Feed Manage. $39: 56-58$

7. Lowe R. Zwart S. 2007. Does the choice of feed phosphate affect pelleting behavior? Feed Compound. 27:20-23.

8. FP\&S Feed Products\& Service Company. FP\&S Feed Products\& Service Company, Feed Products, 2016.

9. "EuroChem." Defluorinated Feed Phosphate (DFP) - EuroChem, 2016, www.eurochemgroup.com/en/product/defluorinated-feed-phosphate-dfp/.

10. Cobb 500 Max Yield Guide, starter, Cobb-Vantress Inc., Siloam Springs, AR.

11. California Pellet Mill Master Model HD Series 1000. CPM Co., Crawfordsville, IN 12. Horizontal cooler, Pyramid Processing Equipment LLC, Stilwell, KS. 
13. WS Tyler Ro-Tap Sieve Shaker One hundred grams of product for each treatment was placed in a dust-tight enclosed series of staked (No. 4, 6, etc.) American Society of Testing and Materials (ASTM) screens affixed to the Ro-Tap particle size analyzer and shaken for $10 \mathrm{~min}$. The screens were then separated and weighed. Particle size was calculated by subtracting the weight of the screen from the final weight of screen and sample after shaking. The mean geometric particle size and log normal geometric SD were calculated as described by McEllhiney (McEllhiney, R. R. 1994. Determining and expressing particle size. Pages 545-547 in Feed Manufacture Technology IV. Am. Feed Ind. Assoc. Inc., Arlington, VA.)

14. Bulk Density is measure in $\mathrm{kg} / \mathrm{m} 3$ and was calculated from a $300 \mathrm{~g}$ sample of product from each treatment. A sample cup measuring $\pi \times 4.452 \times 5.7 \mathrm{~cm}$ was then tared. Next, the product sample was poured into the sample cup reaching maximum capacity and the top was leveled off. The weight of the amount of feed that exactly filled the box was used to determine the bulk density.

15. A model AIR AO1 Imager was used to capture 5x magnification images of the Dicalcium Phosphorus, Nexfos, Bolifor, Deflourinated Phosphorous, and Mixture (1/5 Bolifor, 1/5 MSP, $3 / 5$ DCP).

16. Measures of HPT were obtained by placing an insulated container under the pellet mill chute, catching hot pellets, immediately closing the lid, and use of a thermocouple thermometer and an $80 \mathrm{PK}-24$ temperature probe. A. E. Lamp, A. M. Evans, J. S. Moritz; The effects of pelleting and glucanase supplementation in hulled barley based diets on feed manufacture, broiler performance, and digesta viscosity, The Journal of Applied Poultry Research, Volume 24, Issue 3, 1 September 2015, Pages 295-303. 
17. D. A. Reese, K. L. Foltz, J. S. Moritz; Effect of mixing and sampling method on pelleted feed nutrient analysis and diet formulation validation, The Journal of Applied Poultry Research, Volume 26, Issue 2, 1 June 2017, Pages 219-225

18. NP Analytical Laboratories, St. Louis, MO.

19. Pellet quality was assessed one day following production using the New Holmen Portable Pellet Durability Tester, Lignotech USA, INC., Rothschild, WI. $100 \mathrm{~g}$ of pellets were sifted through No. 5 American Society for Testing and Materials (ASTM) screen and placed in holding chamber, blown for $30 \mathrm{~s}$ by a jet of air, then weighed, giving a direct read of pellet durability. Fine is removed during the blowing process

20. American Society of Agricultural Engineers (ASAE). 1997. ASAE S269.4: Cubes, pellets, and crumbles-Definitions and methods for determining density, durability, and moisture. Standards 1997. Am. Soc. Agric. Eng., St. Joseph, MI. Because of the use of a $3 / 16 \times 1.77$ in. die, pellets were sifted in a No. 6 American Society for Testing and Materials (ASTM) screen. Five hundred grams of sifted pellets were placed in a dusttight enclosure and tumbled for $10 \mathrm{~min}$ at $50 \mathrm{rpm}$. The enclosure was of the dimensions $12 \times 12$ in., with a $2 \times 9$ in. plate affixed diagonally along one of the $12 \times 12$ in. sides. The tumbled samples were then sifted again (No. 6 ASTM) and weighed. The PDI was calculated by dividing the weight of pellets after tumbling by the weight of pellets before tumbling, and then multiplying by 100 . The MPDI was determined in a similar manner, with the exception of adding five $13-\mathrm{mm}$ hex nuts to the pretumbled sample to obtain added pellet agitation.

21. Complete feed was passed through a No. 6 Tyler Sieve. Pellets remaining on sieve were weighed back and calculated as a percentage. 
22. SAS Institute. 2000. The SAS System for Windows 2000. Release 8.1. SAS Inst. Inc., Cary, NC.

23. K. G. S. Wamsley, C. K. Gehring, A. Corzo, E. A. Fontana, J. S. Moritz. 2012. Effects of inorganic feed phosphate on feed quality and manufacturing efficiency. J. Appl. Poult. Res. 21:4, 823-829.

24. Papadopoulos, M. C. 1989. Effect of processing on high-protein feedstuffs: A review. Biol. Wastes 29:123- 138 .

25. S. E. Cutlip, J. M. Hott, N. P. Buchanan, A. L. Rack, J. D. Latshaw, J. S. Moritz. 2008. The Effect of Steam-Conditioning Practices on Pellet Quality and Growing Broiler Nutritional Value. J. Appl. Poult. Res. 17: 2, 249-261.

26. J. S. Moritz, K. R. Cramer, K. J. Wilson, and R. S. Beyer. 2003. Feed manufacture and feeding of rations with graded levels of added moisture formulated to different energy densities. J. Appl. Poult. Res. 12:371-381. 
Table 1. Descriptive data of inorganic feed phosphate ingredients.

\begin{tabular}{|c|c|c|c|}
\hline Treatment & $\begin{array}{c}\text { Particle Size } \\
\text { AVG } \\
(\mu \mathrm{m})^{7}\end{array}$ & $\begin{array}{c}\text { Standard } \\
\text { Deviation AVG }\end{array}$ & $\begin{array}{c}\text { Bulk Density } \\
\left(\mathrm{kg} / \mathrm{m}^{3}\right)^{8}\end{array}$ \\
\hline DCP $^{1}$ & 687.89 & 2.20 & 809.00 \\
\hline Nexfos $^{2}$ & 707.02 & 1.70 & 794.51 \\
\hline Bolifor $^{3}$ & 636.25 & 1.65 & 729.41 \\
\hline Deflourinated Phosphorous $^{4}$ & 357.27 & 1.51 & 1083.62 \\
\hline Mixture $^{5}$ & 469.75 & 2.31 & 719.68 \\
\hline Bolifor $+\mathrm{SiO} 2^{6}$ & 321.23 & 2.50 & 235.93 \\
\hline
\end{tabular}

${ }^{1} \mathrm{FP} \& \mathrm{~S}$ Dicalcium Phosphorus $=18.5 \% \mathrm{P}$ and $23 \% \mathrm{Ca}$,

${ }^{2}$ Nexfos; Mossaic $=19 \% \mathrm{P}, 16.5 \% \mathrm{Ca}$ and $4.5 \% \mathrm{Na}$,

${ }^{3}$ Bolifor; Yara $=22.7 \% \mathrm{P}$ and $16 \% \mathrm{Ca}$.

${ }^{4}$ Deflourinated Phosphorous; Yara $=18 \% \mathrm{P}$ and $30 \% \mathrm{Ca}, 5.3 \% \mathrm{Na}$,

${ }^{5}$ Mixture (1/5 Bolifor, $\left.1 / 5 \mathrm{MSP}, 3 / 5 \mathrm{DCP}\right)$; Yara $=20.4 \% \mathrm{P}, 17.1 \% \mathrm{Ca}$ and $4.0 \% \mathrm{Na}$,

${ }^{6}$ Bolifor + sand $(80: 20) ; \mathrm{Yara}=22.7 \% \mathrm{P}$ and $16 \% \mathrm{Ca}-$ formulated on a digestible $\mathrm{P}$ basis to be equivalent to the DCP diet

${ }^{7}$ WS Tyler Ro-Tap Sieve Shaker One hundred grams of product for each treatment was placed in a dust-tight enclosed series of staked (No. 4, 6, etc.) American Society of Testing and Materials (ASTM) screens affixed to the Ro-Tap particle size analyzer and shaken for $10 \mathrm{~min}$. The screens were then separated and weighed. Particle size was calculated by subtracting the weight of the screen from the final weight of screen and sample after shaking. The mean geometric particle size and $\log$ normal geometric SD were calculated as described by McEllhiney (McEllhiney, R. R. 1994. Determining and expressing particle size. Pages 545-547 in Feed Manufacture Technology IV. Am. Feed Ind. Assoc. Inc., Arlington, VA.) ${ }^{8}$ Bulk Density is measure in $\mathrm{kg} / \mathrm{m} 3$ and was calculated from a $300 \mathrm{~g}$ sample of product from each treatment. A sample cup measuring $\pi \times 4.45^{2} \times 5.7 \mathrm{~cm}$ was then tared. Next, the product sample was poured into the sample cup reaching maximum capacity and the top was leveled off. The weight of the amount of feed that exactly filled the box was used to determine the bulk density. 
Table 2. . Basal + Dicalcium P, Basal + Nexfos, Basal + Bolifor, Basal + Deflourinated Phosphorous, Basal + Mixture, and $\mathrm{Basal}+\mathrm{Bolifor} \& \mathrm{SiO}_{2}$ diet formulations with selected calculated and analyzed nutrients.

\begin{tabular}{|c|c|c|c|c|c|c|}
\hline Ingredients & $\begin{array}{c}\text { Basal }^{1}+ \\
\text { Dicalcium } \\
\mathrm{P}^{4} \\
\end{array}$ & $\begin{array}{l}\text { Basal }^{1}+ \\
\text { Nexfos }^{5}\end{array}$ & $\begin{array}{l}\text { Basal }^{1+} \\
\text { Bolifor }^{6}\end{array}$ & $\begin{array}{c}\text { Basal }^{1}+ \\
\text { Deflourinated } \\
\text { Phosphorous }^{7}\end{array}$ & $\begin{array}{l}\text { Basal }^{1}+ \\
\text { Mixture }^{8}\end{array}$ & $\begin{array}{c}\text { Basal }^{1}+ \\
\text { Bolifor \& } \mathrm{SiO}_{2}{ }^{9} \\
\end{array}$ \\
\hline \multicolumn{7}{|c|}{ Inclusion (\%) } \\
\hline Corn & 57.21 & 57.21 & 57.21 & 57.84 & 57.21 & 57.20 \\
\hline Soybean Meal $(48 \%)$ & 29.43 & 29.43 & 29.43 & 29.43 & 29.43 & 29.43 \\
\hline Corn DDGS & 6.00 & 6.00 & 6.00 & 6.00 & 6.00 & 6.00 \\
\hline Soybean oil ${ }^{3}$ & 2.89 & 2.89 & 2.89 & 2.68 & 2.89 & 2.90 \\
\hline DL-Methionine & 0.34 & 0.34 & 0.34 & 0.34 & 0.34 & 0.34 \\
\hline Vitamin Mineral Premix & 0.25 & 0.25 & 0.25 & 0.25 & 0.25 & 0.25 \\
\hline Sodium Bicarbonate & 0.10 & 0.10 & 0.10 & 0.10 & 0.10 & 0.10 \\
\hline Lysine & 0.35 & 0.35 & 0.35 & 0.35 & 0.35 & 0.35 \\
\hline Threonine & 0.21 & 0.21 & 0.21 & 0.21 & 0.21 & 0.21 \\
\hline Feed Phosphate & 1.26 & 1.23 & 1.03 & 1.29 & 1.14 & $\begin{array}{c}0.70 \\
\text { Bolifor }\end{array}$ \\
\hline & & & & & & $\begin{array}{c}0.43 \\
\mathrm{SiO} 2 \\
\end{array}$ \\
\hline Limestone & 1.69 & 1.86 & 1.92 & 1.42 & 1.92 & 1.83 \\
\hline Salt & 0.26 & 0.12 & 0.26 & 0.08 & 0.14 & 0.26 \\
\hline \multicolumn{7}{|l|}{ Calculate Nutrients } \\
\hline $\mathrm{ME}^{1}(\mathrm{kcal} / \mathrm{kg})$ & 3,000 & 3,000 & 3,000 & 3,000 & 3,000 & 3,000 \\
\hline Crude Protein, (\%) & 20.00 & 20.00 & 20.00 & 20.00 & 20.00 & 20.00 \\
\hline Dig. Lysine ${ }^{2}(\%)$ & 1.20 & 1.20 & 1.20 & 1.20 & 1.20 & 1.20 \\
\hline Dig. Methionine ${ }^{2}(\%)$ & 0.63 & 0.63 & 0.63 & 0.63 & 0.63 & 0.63 \\
\hline $\begin{array}{l}\text { Dig. Methionine }+ \\
\text { cysteine }(\%)\end{array}$ & 0.90 & 0.90 & 0.90 & 0.90 & 0.90 & 0.90 \\
\hline Dig. Threonine ${ }^{2}(\%)$ & 0.84 & 0.84 & 0.84 & 0.84 & 0.84 & 0.84 \\
\hline Dig. Tryptophan $2(\%)$ & 0.20 & 0.20 & 0.20 & 0.20 & 0.20 & 0.20 \\
\hline Calcium, $(\%)$ & 1.01 & 0.99 & 0.97 & 1.01 & 1.00 & 0.88 \\
\hline Phosphorus, (\%) & 0.62 & 0.62 & 0.62 & 0.62 & 0.62 & 0.55 \\
\hline Calcium:Phosphorus ratio $^{1}$ & $1.62: 1$ & $1.58: 1$ & $1.56: 1$ & $1.62: 1$ & $1.61: 1$ & $1.61: 1$ \\
\hline Available $\mathrm{P}-\mathrm{nPP}^{1}$ & 0.36 & 0.36 & 0.36 & 0.36 & 0.36 & 0.29 \\
\hline Sodium, $(\%)$ & 0.17 & 0.17 & 0.17 & 0.17 & 0.17 & 0.17 \\
\hline \multicolumn{7}{|l|}{ Analyzed Nutrients ${ }^{10}$} \\
\hline Calcium, $\%$ & 0.95 & 0.92 & 0.82 & 1.02 & 0.90 & 0.78 \\
\hline Phosphorus, \% & 0.58 & 0.57 & 0.55 & 0.60 & 0.58 & 0.48 \\
\hline Available P-nPP, $\%$ & 0.33 & 0.31 & 0.32 & 0.35 & 0.33 & 0.24 \\
\hline
\end{tabular}

${ }^{1}$ Metabolizable Energy and Available Phosphorus were based on Agristat values as suggested by M. Donohue. 2013. The Challenges in Feeding Broilers in Times of High and Volatile Feed Ingredient Costs: How to Cover the Costs?. 2013 Mid-Atlantic Nutrition Conference proceedings. 
${ }^{2}$ Digestible amino acids were based on the digestible lysine value $(1.2 \%)$ suggested by P. B. Tillman and W.A. Dozier. 2013. Current Amino Acid Considerations for Broilers: Requirements, Ratios, Economics. www.thepoultryfederation.com for $8-14$ day broilers. Therefore digestible lysine was set at $1.08 \%$. Digestible amino acid to digestible lysine ratios followed further recommendations of this communication (minimum of 0.54 methionine, 0.90 TSAA, 0.84 threonine, 0.19 tryptophan).

${ }^{3}$ Soybean oil will be added at $0.5 \%$ at the mixer with the remaining soybean oil $2.69 \%$ being added post pelleting 4FP \&S Dicalcium Phosphorus $=18.5 \% \mathrm{P}$ and $23 \% \mathrm{Ca}$,

${ }^{5}$ Nexfos; Mossaic $=19 \% \mathrm{P}, 16.5 \% \mathrm{Ca}$ and $4.5 \% \mathrm{Na}$,

${ }^{6}$ Bolifor; Yara $=22.7 \% \mathrm{P}$ and $16 \% \mathrm{Ca}$.

${ }^{7}$ Deflourinated Phosphorous; Yara $=18 \% \mathrm{P}$ and $30 \% \mathrm{Ca}, 5.3 \% \mathrm{Na}$,

${ }^{8}$ Mixture (1/5 Bolifor, 1/5 MSP, 3/5 DCP); Yara $=20.4 \% \mathrm{P}, 17.1 \% \mathrm{Ca}$ and $4.0 \% \mathrm{Na}$,

${ }^{9}$ Bolifor + sand $(80: 20)$; Yara $=22.7 \% \mathrm{P}$ and $16 \% \mathrm{Ca}$ - formulated on a digestible $\mathrm{P}$ basis to be equivalent to the DCP diet

${ }^{10}$ NP Analytical Laboratories, St. Louis, MO. 


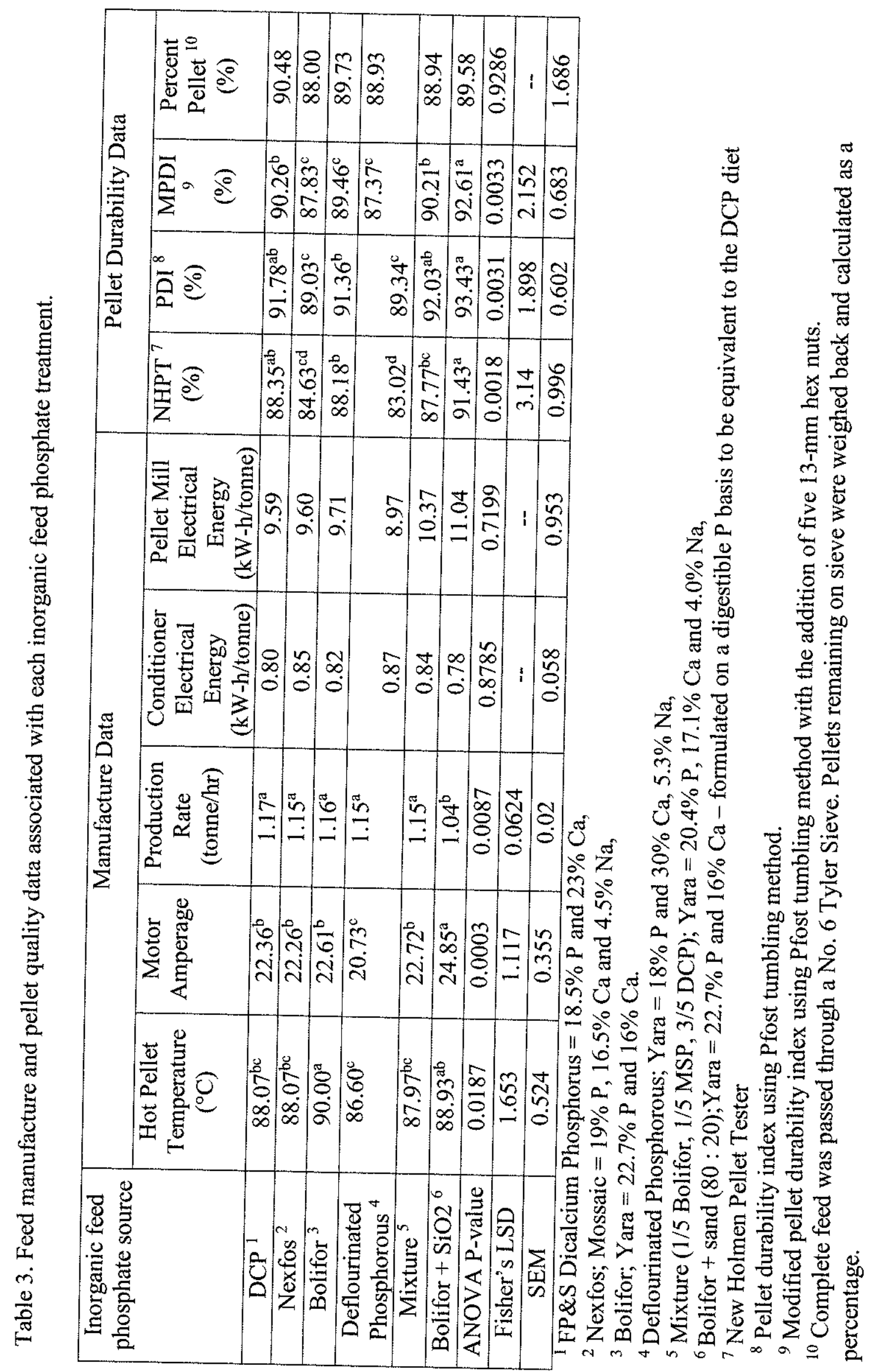



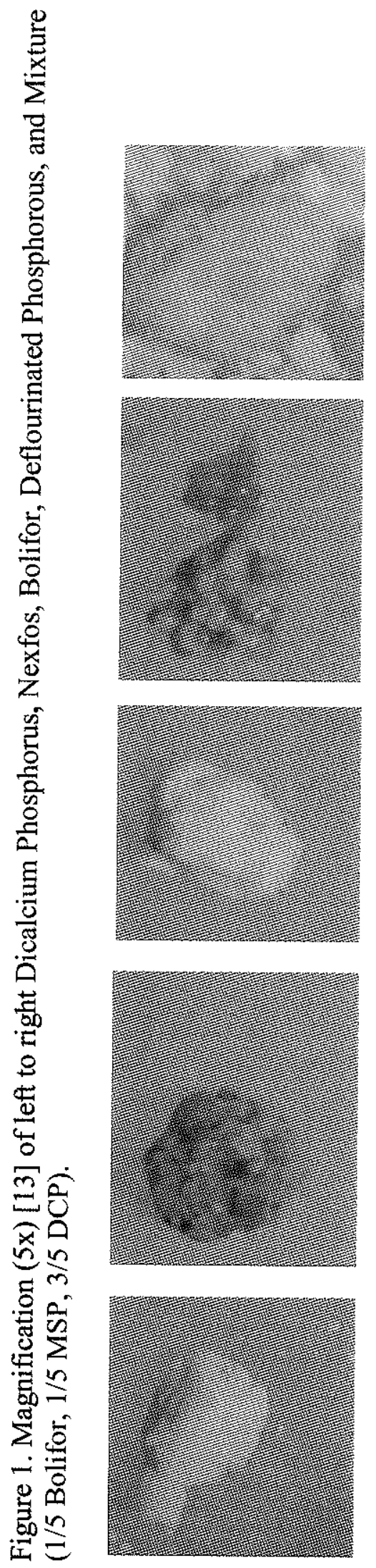


\title{
CIRRICULUM VITAE
}

\section{Ariel N. Bergeron}

\author{
1025 Coteau Rd \\ Houma, LA \\ 70364
}

Anb0040@mix.wvu.edu

\section{EDUCATION}

MASTER OF SCIENCE

Animal and Food Science

YEARS ATTENDED (EX: 2016-2017)

West Virginia University

Morgantown, West Virginia

(985)790-0405

Thesis: Thermal Processes of Pellets and Feed Phosphate Variations in Diets on Feed Manufacture and Broiler

Performance

BACHELOR OF SCIENCE

Animal, Dairy and Poultry Science

Louisiana State University

YEARS ATTENDED (EX 2012-2016)

Baton Rouge, Louisiana

\section{EDUCATION HONORS/AWARDS}

\section{Terrebonne High School Graduate}

2012

Houma, Louisiana

- National Honors Society Member, Terrebonne High School Chapter 2009-2012

- $4 \mathrm{H}$ State Executive Board Member, Louisiana 4H

- $4 \mathrm{H}$ State Food and Fitness Board Member, Louisiana 4H

\section{Scholarships/Grants Received}

- Taylor Opportunity Program for Students (TOPS) 2012-2016

- Louisiana Egg Commission Scholarship Recipient 2013-2014

- Hubbard Farm Scholarship Recipient

2014-2015

- Louisiana Poultry Federation Scholarship Recipient 2014-2016 


\section{Awards and Honors}

- Jones-Hamilton Undergraduate Travel Grant Recipient 2015-2016

- LSU Les Voyageurs KC Toups Memorial Award 2015-2016

- LSU Discover Scholar Undergraduate Research Awardee 2015-2016

- LSU Undergraduate Research Conference 2015-2016

- 2nd Place in Life Science Division II Category

- National Collegiate Poultry Judging Contest 2015-2016

- 4th Place Individual

- National Collegiate Poultry Judging Contest 2015-2016

- High Individual in Carcass Quality and Breed Selection

- LSU College of Agriculture Research Grant Recipient 2015-2016

- Poultry Science Association Undergraduate Certificate of Participation 2015-2016

- LSU Student Government; College of Agriculture Senator 2015-2016

- Leadership LSU 2015-2016

- Member

- LSU Meat Science Quiz Bowl 2015-2016

- Member

- Poultry Science Association Certificate of Excellence Award 2015-2016

- LSU College of Agriculture Les Voyageur; 2014-2016

- Executive Committee, Marketing and Communications Branding Chair

- Poultry Science Association Southwest Regional Ambassador 2014-2016

- Poultry Science Association Undergraduate Certificate of Participation 2014-2015

- Poultry Science Association Certificate of Excellence Award 2014-2015

- Phis Sigma Theta National Honor Society Member 2014-2016

- The Society for Collegiate Leadership and Achievement 2014-2016

- LSU College of Agriculture Research Grant Recipient 2013-2014

\section{PUBLICATIONS}

\section{Submitted for Peer Review}

A. N. Bergeron, J. W. Boney, B. G. Glover, and J. S. Moritz. 2017. The effects of diet formulation and thermal processes associated with pelleting on $18 \mathrm{~d}$ broiler performance and digestible amino acid concentration. JAPR

\section{Paper in Preparation}

A. N. Bergeron, A. E. Lamp, J. W. Boney, B. G. Glover and J. S. Moritz. 2017. The effects of Various Inorganic Phosphate Feed Ingredients on Feed Manufacture and Pellet Quality. JAPR

\section{Abstracts}

A. N. Bergeron, J. W. Boney, and J. S. Moritz. 2017. The effects of diet formulation and thermal processing associated with pelleting on 18 -d broiler performance and amino acid digestibility. Poult. Science. (Accepted Abstract (8))

J. W. Boney, A. N. Bergeron, and J. S. Moritz. 2017. The effects of varying long-term steam conditioning temperature and antimicrobial inclusion on the mitigation of Enterococcus faecium 8459, a non-pathogenic surrogate of Salmonella. Poult. Science. (Accepted Abstract (60)) 
A.N. Bergeron, J.W. Boney, B.G. Glover, and J. S. Moritz. 2017. Diet formulation and feed processing effects on 18-d broiler performance. Poult. Sci. (Accepted Abstract (85)).

B.G. Glover, J.M. Hadfield, J.W. Boney, A.N. Bergeron, and J.S. Moritz. 2017. Effects of environment, feed form, and caloric density on energy partitioned to performance and immune response. Poult. Sci. (Accepted Abstract (86)).

A.N. Bergeron, J.W. Charal, and T.A. Lavergne. 2016. Determining the lysine requirement of 0 to 28 day old bobwhite quail. Poult. Sci. 95 (E-Suppl.1)

A.N. Bergeron, J.W. Charal, and T.A. Lavergne. 2015. Determining the lysine requirement of 7 to 28 day old bobwhite quail. Poult. Sci. 94 (E-Suppl.1)

A.N. Bergeron, J.W. Charal, and T.A. Lavergne. 2014. A method to rear 0 to 21 day old bobwhite quail. Poult. Sci. 93 (E-Suppl.1): 98

\section{RESEARCH EXPERIENCE}

\section{National Meeting Paper Presentations}

- 2017 Poultry Science Association Annual Meeting (Orlando, Florida)

$>$ "The effects of diet formulation and thermal processing associated with pelleting on 18-d broiler performance and amino acid digestibility"

- 2017 International Poultry Production Expo (Atlanta, GA)

$>$ "Diet formulation and feed processing effects on 18-d broiler performance"

- 2016 Poultry Science Association Annual Meeting (New Orleans, LA)

$>$ "Determining the lysine requirement of 0 to 28 day old bobwhite quail"

- 2015 Poultry Science Association Annual Meeting (Louisville, KY)

$>$ "Determining the lysine requirement of 7 to 28 day old bobwhite quail"

- 2014 Poultry Science Association Annual Meeting (Corpus Christi, TX)

$>$ "A method to rear 0 to 21 day old bobwhite quail"

\section{Regional Meeting Poster Presentations}

- 2017 Animal and Plant Science Poster Session

$>$ "The effects of diet formulation and thermal processing associated with pelleting on 18-d broiler performance and amino acid digestibility"

- 2017 Davis College Student Research and Creative Scholarship Day

$>$ "Diet formulation and feed processing effect on 18-d broiler performance"

- 2016 Gamma Sigma Delta Research Competition

$>$ "Determining the lysine requirement of 0 to 28 day old bobwhite quail"

- 2016 LSU Discover Day

$>$ "Determining the lysine requirement of 0 to 28 day old bobwhite quail"

- 2015 LSU Undergraduate Research Conference

$>$ "Determining the lysine requirement of 7 to 28 day old bobwhite quail"

- 2015 LSU Discover Day

"Determining the lysine requirement of 7 to 28 day old bobwhite quail"

- 2014 Gamma Sigma Delta Research Competition

$>$ "A method to rear 0 to 21 day old bobwhite quail" 


\author{
$>$ Duties \\ - Assisting the instructor in preparation of course materials and exams \\ - Grading assignments and exams \\ - Organizing weekly lab meetings \\ - Research feed manufacture operations \\ - General feed mill maintenance \\ - Ingredient sourcing \\ - Feed mill demonstrations, tours, and teaching \\ - Feed mill cleaning and organization \\ - Scheduling research feed manufacture
}

\title{
Graduate Teaching Assistant
}

- Teaching Assistant for ANPR 338- Poultry Judging

$>$ Roles included instructing classes and selecting top individuals to compete in the National Poultry Judging Competition. The position also included in taking the top individuals to Baton Rouge, LA for the National Poultry Judging Competition, setting up the competition and grading participants score cards.

- Team Awards

- 3rd Place High Team Production

- 4th Place High Team Breed Selection

- 5th Place Overall Team

$\circ \quad$ Individual Awards

- 1st Place Individual Live Birds

- 5 th Place Individual Breed Selection

- Teaching Assistant for ANNU 362- Advance Applied Animal Nutrition

$>$ Roles included assisting students as they gained knowledge of poultry operations and organize feed analysis that allowed students to obtain first-hand experience of how to use various laboratory utensils.

\section{Graduate Research}

- Led a contract study with Yara to evaluate feed manufacture and pellet quality attributes of six different phosphorus/calcium sources in corn, soybean meal, and corn DDGS based diets 2017

- Led an in-house experiment to determine the effects of feed formulation and feed manufacturing on broiler performance and amino acid digestibility 2016

- Assisted numerous graduate and undergraduate students with research experiments 2016-present

$>$ Diet formulation

$>$ Ingredient sourcing

$>$ Feed manufacture

$>$ Sample collection

- Feed sample collection throughout feed manufacture

- Tibiae collection

- GI tract content collection

- Lower ileum content collection 


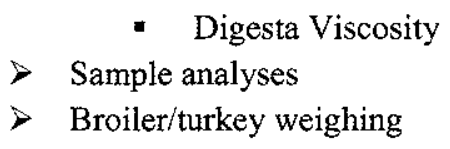

- International Poultry Production Expo

$>$ 2017- Atlanta, GA

- Poultry Science Association annual meeting attendee

$>$ 2017-Orlando, FL

\section{Undergraduate Researcher}

- Led an in-house experiment to determine the lysine requirement of 0 to 28 day old bobwhite quail. 2016

- Led an in-house experiment to determine the lysine requirement of 7 to 28 day old bobwhite quail. 2015

- Led an in-house experiment to determine a method to rear 0 to 21 day old bobwhite quail. 2014

- Assisted numerous graduate and undergraduate students with research experiments 2012-2016

$>$ Diet formulation

$>$ Ingredient sourcing

$>$ Feed manufacture

$>$ Sample collection

- Feed sample collection throughout feed manufacture

- Tibiae collection

- GI tract content collection

- Lower ileum content collection

- Drawing blood

- Hot breast extraction

- Breast yield determination

- Lesion scoring

$>$ Sample analyses

$>$ Broiler/quail weighing

- Poultry Science Association annual meeting attendee

$>$ 2016- New Orleans, LA

$>$ 2015-Louisville, KY

$>$ 2014- Corpus Christi, TX

\section{State Extension Activities}

- FFA Career Development Event

- Monongalia County (WV) Fair- Poultry Exhibit Judge 2017

- Ag Safety Day -Preston County (WV) 2017

- WVU Family Farm Day

- Davis College Welcome Back BBQ 2016-2017

$>$ Rear and process broilers

$>$ Prepare/Deliver Food

- International Poultry Exposition, Atlanta, GA

2012-2017

- Led numerous WVU Animal Science Farm tours

2016-present 
- Louisiana State 4H Poultry Judging Team Workshop

$>$ Students were to represent Louisiana at the state $4-\mathrm{H}$ poultry judging competition

- $\mathrm{Ag}$ in the Classroom

- Louisiana State 4H Poultry Judging Contest

- Assisted with conducting an annual poultry judging competition

- Organized competition and scheduling

- Louisiana State 4H Livestock Show; Poultry Exhibit

- Organized exhibition entries

- Assisted in judging exhibition

- Louisiana Poultry Seminar

- Organized seminar and trade show

- Assisted with seminar set up and sign in

\section{EXPERIENCE}

LSU Animal Science Department; Student Research Assistant

Assist in various research trials by collecting, analyzing and recording data

- Assist in formulating diets for nutritional projects

- Conduct research on proper care and husbandry for various poultry and wild game bird

- Assist staff members in coordinating office procedures and activities

- Maintain personal research projects on care, maintenance and nutritional requirements of Bobwhite Quail

National Turkey Federation Internship Program | Washington, D.C.

- Attend meetings with other trade organizations

- Attend Congressional hearings and briefings

- Work with membership database to understand the composition of membership

- Working with various social media outlets to reach stakeholders

- Assist Governmental Affairs teams with critical projects

LSU Poultry Judging Team Member

- University of Arkansas National Poultry Judging Competition (2012)

- $4^{\text {th }}$ place Team

- $15^{\text {th }}$ Individual overall

- Louisiana State University National Poultry Judging Competition (2013)

- $4^{\text {th }}$ place team

- $12^{\text {th }}$ individual overall

- University of Arkansas National Poultry Judging Competition (2015)

$\circ 4^{\text {th }}$ individual overall

- $3^{\text {rd }}$ place Team

- High Individual for Breed Selection and Carcass Quality 


\section{SKILLS}

- Time management

- Teaching/Instructing

- Ingredient sourcing and purchasing

- Proficient in Window's Microsoft Programs

- Nucleic acid extraction

- Public speaking

- Poultry judging, handling, and husbandry

- Feed manufacture

- Pellet mill operations

- Diet formulation

- Area specific courses completed/in progress:

$>$ A\&VS 490- Teaching Practicum (Advanced Applied Nutrition)

$>$ A\&VS 690- Teaching Practicum (Poultry Judging)

$>$ A\&VS 797- Research

$>$ A\&VS 595-Independent Study

$>$ A\&VS 451-Current Literature in Animal Science

$>$ AGBI 512- Nutritional Biochemistry

$>$ AGBI 513-Nutritional Biochemistry Lab

$>$ AGBI 514- Animal Biotechnology

$>$ AGBI 514L-Animal Biotechnology Lab

$>$ HN\&F 614- Nutrition and Disease Prevention

$>$ STAT 511-Statistical Methods 1

$>$ STAT 512-Statistical Methods 2

\section{PROFESSIONAL REFERENCES}

\section{Dr. Theresia Lavergne \\ Monogastric Nutritionist \\ Baton Rouge, LA \\ 225-281-9450 \\ Theresia.lavergne@churchdwight.com}

\section{Dr. Joseph Moritz}

Professor of Poultry Science at WVU

Morgantown, WV

724-880-1639

Joe.moritz@mail.wvu.edu

\section{Dr. Janet Tou}

Professor of Human Nutrition Foods

Morgantown, WV

304-293-191

Janet.Tou@mail.wvu.edu
- Experimental design

- Cecectomy surgery

- Tibia extraction

- Gastrointestinal tract extraction

- Poultry processing

- Bobwhite quail rearing

- Brookefield Viscometer experience

- Pellet durability analysis

- Ether extraction using Soxhlet apparatus

- Poultry vaccination experience 